\title{
Synthesis and Properties of a Polymer-Modified Material for Thin Spray-On Liners in Mine Roadways
}

\author{
Lianjun Chen $\mathbb{D}^{1,2,3}$ Xuekai Jiang, ${ }^{1}$ Zhaoxia Liu $\mathbb{D}^{1},{ }^{1,2}$ Xiangfei Cui $\mathbb{D}^{1,},{ }^{1,2}$ Guoming Liu $\left(\mathbb{D},{ }^{1}\right.$ \\ Zhi Zhou, ${ }^{1}$ and Qizheng Dong ${ }^{1}$ \\ ${ }^{1}$ College of Safety and Environmental Engineering, Shandong University of Science and Technology, Qingdao 266590, China \\ ${ }^{2}$ State State Key Laboratory of Mining Disaster Prevention and Control Co-founded By Shandong Province and \\ Ministry of Science and Technology, Shandong University of Science and Technology, Qingdao 266590, China \\ ${ }^{3}$ National Demonstration Center for Experimental Mining Engineering Education, \\ Shandong University of Science and Technology, Qingdao 266590, China \\ Correspondence should be addressed to Zhaoxia Liu; zhaoxialiu@163.com and Xiangfei Cui; cuixf11@163.com
}

Received 3 January 2020; Accepted 21 May 2020; Published 16 June 2020

Academic Editor: Alicia E. Ares

Copyright ( $) 2020$ Lianjun Chen et al. This is an open access article distributed under the Creative Commons Attribution License, which permits unrestricted use, distribution, and reproduction in any medium, provided the original work is properly cited.

\begin{abstract}
In order to adapt to dry and wet environment in mine roadways and improve the performance of sealing materials under different environmental conditions, this study selected the materials based on their ability to spray and found that the materials with a viscosity of 1500-6000 MPa.s can achieve a balance between performance of spray and wall-hanging performance. Next, by selecting high-elastic polyacrylate emulsion and ordinary Portland cement as the film-forming agent and gel, respectively, mix proportion factors of the nonreactive thin spray-on liner (TSL) were analyzed by using the Taguchi method. Moreover, fluidity, setting time, sealing properties, compressive strength, bending strength, and bonding strength of those materials were measured. It was disclosed that addition of an appropriate amount of polyacrylate emulsion can enhance the effects of fibers. By observing the morphologies of the materials' bonding surfaces and comparing the factors influencing bonding strength between both dry and wet walls, it was uncovered that the adhesive property of cement-based sealing materials was mainly affected by the water-cement ratio. Eventually, bonding strength and sealing properties were selected as primary optimization indexes, while setting time, bending strength, and compressive strength were selected as secondary optimization indexes. The appropriate proportions of two types of TSLs for dry and wet walls were $(\mathrm{W} / \mathrm{C}=50 \% ; \mathrm{P} / \mathrm{C}=6 \% ; \mathrm{F} / \mathrm{C}=1 \% ; \mathrm{T} / \mathrm{C}=0.2 \%)$ and $(\mathrm{W} / \mathrm{C}=45 \% ; \mathrm{P} / \mathrm{C}=6 \% ; \mathrm{F} / \mathrm{C}=1 \%$; $\mathrm{T} / \mathrm{C}=0.4 \%)$, respectively. A prepared TSL can be used for filling rock fractures in mine roadways. In addition, TSL exhibited a great performance for dry and wet walls under different environmental conditions. The present study may provide an insightful guidance and reference for the investigation of TSL sealing materials applied in the mine roadways.
\end{abstract}

\section{Introduction}

As early as in the 1990s, thin spray-on liners (hereinafter referred to as TSLs) have been first used in Canadian mines for sealing roadways [1], so as to prevent weathering of rocks in roadways and avoid accidents induced by rock falling [2-5]. The use of TSLs in the roadway is shown in Figure 1(a). In previous projects, anchor networks and concretes were generally used in mine roadways for surface sealing. However, anchor networks can only play the role of passive protection and are easily corroded, accompanied by a great labor intensity in installation. Mass construction materials should be transported for spraying concretes, in which the dry spraying technique causes serious dust hazards in the construction, while wet spraying technique requires complex devices and easily leads to the blockage in the pipes. Moreover, concrete support liners have a remarkable weight, which can easily impose safety threats after bonding failure [6-12]. In contrast to traditional methods, TSL-based sealing technique possesses a series of advantages, mainly including less amount of utilization, favorable filling and enclosing performance, high bonding 


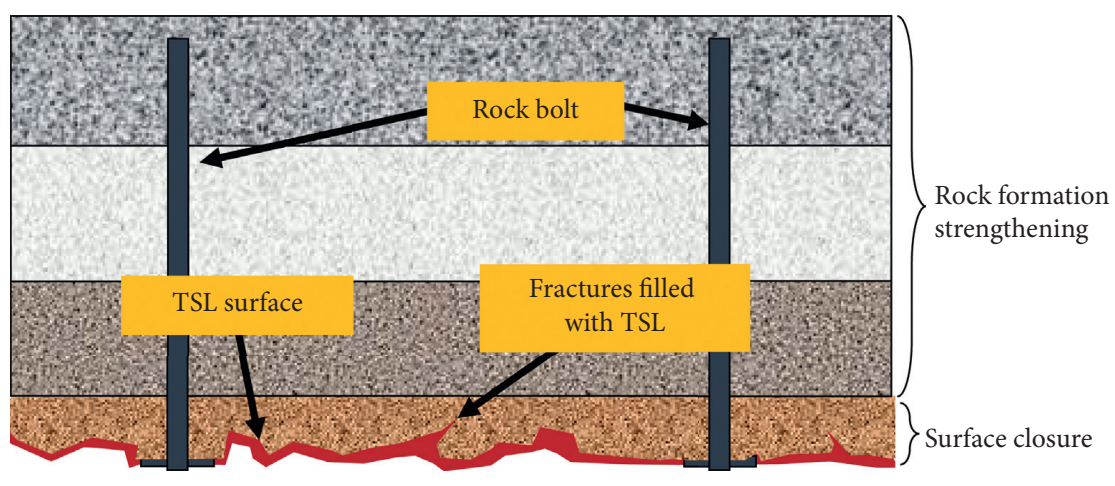

(a)

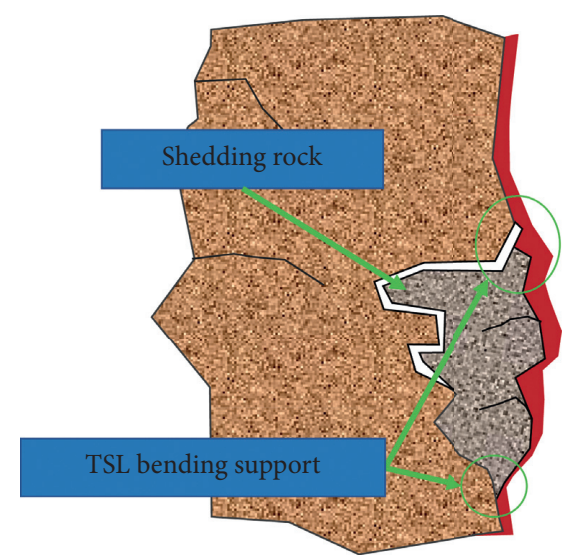

(b)

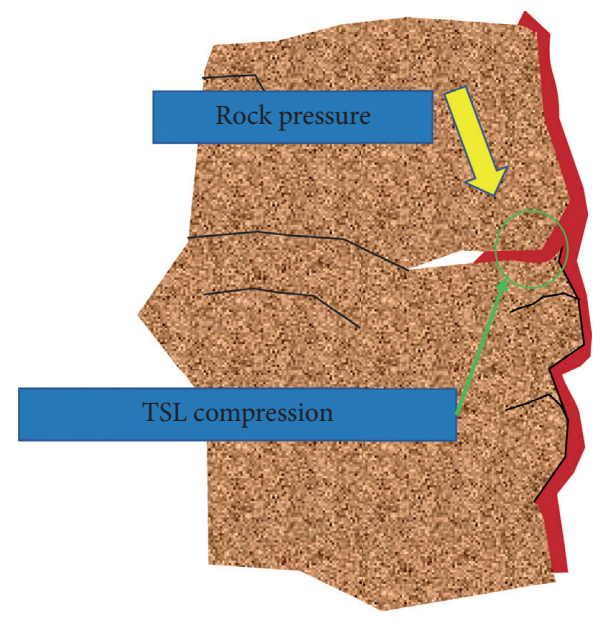

(c)

Figure 1: (a) Schematic diagram of TSL use in the roadway. (b) TSL basket action. (c) TSL wedge action.

strength, user-friendly construction, and rapid solidification $[13,14]$.

In addition to the prevention of weathering, $\mathrm{Li}$ et al. adopted TSLs for sealing in gaseous mines and found that TSL sealing increased gas extraction yield and purity [15]. Komurlu sprayed TSL in the tunnel, and then blasted that tunnel; according to the results, the spraying of TSL reduced the effect of blasting on the surrounding rock [16]. The authors in $[17,18]$ achieved similar conclusions. In order to satisfy special requirements under different environmental conditions, different types of TSLs exhibited some personalized functions, such as favorable gas enclosure performance and excellent wall self-cleaning capability [19-22]. Therefore, TSLs were endowed with unique competitive advantages and significantly attracted scholars' attention. The promotion of a TSL-based sealing technique in the mine tunnels will face a variety of environmental conditions (e.g., rock fracture and seepage) [23-25]; however, the optimization of TSLs for wet wall surfaces was poorly studied.

A number of scholars examined the action mechanisms of TSLs and concluded some performance-based indexes that should be seriously taken into consideration. Stacey and $\mathrm{Yu}$ found that filling cracks in rocks by TSLs remarkably enhanced the strength [26]. Depth of filling with TSL materials mainly depends on fluidity and injection pressure, as well as openness and orientation of rock cracks. For TSL materials with low viscosity, the cracks exhibited greater depth of filling, which can enhance the connection. Therefore, the flowability needs to be investigated in depth. Ozturk and Tannant and Chen et al. conducted some related bonding experiments and concluded that the bonding strength between rock matrix and TSL materials was more important for coating's enhancement than the mechanical lock $[27,28]$. Both bonding strength and viscosity, as two performance-based indexes for TSLs, should be meticulously examined. Stacey and Yu numerically studied the effects of filling with TSL materials on cracks in rocks [26]. They demonstrated that the modulus of elasticity of a cracked rock after injecting materials into its pores was equal to the uncracked rock. According to their theoretical results, Fowkes et al. found that filling materials with low modulus of elasticity can effectively prevent the propagation of cracks and further rock failure [29]. Pan and Xiong conducted compressive and bending tests on the repaired rock and expressed that the addition of filling materials with comparable strength to the matrix can remarkably enhance the rock's integrity and reduce further fracturing [30]. The enhancement of stability by sealing material's bending and 
compressive capabilities still needs to be further investigated. In combination with capabilities of TSL materials, Stacey analyzed an interaction between TSL materials and rocks and proposed the "promotion of block interlock" [31]. Lin pointed out that TSLs can achieve wedge effect through selfproperties (Figure 1(c)) and also act as a bearing basket for invalid rocks (Figure 1(b)) [32]. Ferreria and Piroddi and Mpunzi et al. also performed similar theoretical studies $[33,34]$. The abovementioned studies can provide a theoretical foundation for studying the effects of TSL sealing materials on cracked rocks; however, the bonding mechanism under humid condition has been rarely investigated. Therefore, this study attempted to explore the bonding mechanism of TSL materials under different environmental conditions in combination with dry and humid environments, which can provide a reliable reference for application of TSL materials in mine roadways.

In addition, TSLs have been continuously developed theoretically and experimentally. TSL materials can be divided into two types: reactive and nonreactive. Reactive TSL materials mainly contain two-component polyurethane, including polyurea and acrylic acid [35]. The advantages lie in hard-coating films with a remarkable strength formed in chemical reactions. However, the disadvantages are also obvious; i.e., a sprayer can only operate at high temperature in order to maintain the stability in the reaction or produce poisonous and hazardous gas [36]. These challenges can hardly be addressed in underground mines. Jensen used reactive TSL materials in metal mine tunnels; however, the produced irritant gas can hardly be discharged [37]. Zhou et al. prepared TSLs with favorable dust adsorption functions through graft copolymerization of acrylic acid and polyaluminium chloride [19]; unfortunately, the reaction conditions were inconveniently realized under actual conditions in underground mines. Nonreactive TSL materials can be prepared by different film-forming agents after the addition of various types of gel materials [38, 39]. The TekFlfex prepared by Falconbridge Co., Ltd. (Toronto, Canada) is a kind of cement-based TSL materials [20, 35, 40]. Chang et al. used an emulsion powder and cement to prepare TSL materials and changed the polymer content in the materials [41]. Due to the high ductility of the polymer, the ductility of the prepared composites was improved and the bending strength of the mortar specimen was enhanced by over $20 \%$, while compressive strength of the prepared TSLs was simultaneously reduced. In addition, Chang et al. obtained similar findings [42]. Zhang et al. prepared TSL materials by mixing the powder polymer and cement; they experimentally found that the prepared TSL materials can be bent by $90^{\circ}$ without any damage [43]. With respect to the selection of film-forming agents, emulsion, liquid resin, and polymer emulsion or powder are commonly used materials. It has been proved that performance of an emulsion is not satisfactory enough and may cause damage to individuals' health [38]. Because of the greater expansion coefficient of the resin than the rock, it is easily cracked [44]. A polymer emulsion is a colloidal dispersion of discrete polymer particles with a typical particle diameter of $0.01-1.0$ microns in a medium (e.g., water). It is recognized as the most promising material when using as a film-forming agent in TSL materials. In particular, at present, polypropylene is extensively utilized as a supplementary agent for increasing the toughness of cement owing to excellent weather resistance, being environment friendly, and degree of toughness $[45,46]$. A great number of experimental studies revealed that the addition of a polyacrylate emulsion can improve the microstructure of cement paste. Meanwhile, the added polyacrylate emulsion can react with $\mathrm{Ca}^{2+}$ during hydration process of cement, thereby forming carboxylate. In other words, the combination of $\mathrm{Ca}^{2+}$ with $-\mathrm{COO}^{-}$can enhance toughness, penetration resistance, and freeze-thaw resistance of cement [47-49]. Outstanding performance of polyacrylate has also been widely acknowledged [50]. According to Ohama's model, polymer molecules can impose negative influences on the initial reaction of gel materials [51]; however, as a kind of primary TSL materials, nonreactive materials exhibit unique superiorities in terms of low-cost, easy preparation, and application, as well as healthcare utilization.

In summary, the present study concentrated on mine roadways with great susceptibility to weathering and aimed to enhance the operating performance of TSL materials in tunnels under both dry and wet conditions. First, the polyacrylate emulsion and ordinary Portland cement with high modulus of elasticity were selected as a film-forming agent and gel, respectively, and sprayability-based screening was performed. Next, those factors influencing TSL were analyzed by using the Taguchi method [44, 52-55]. The viscosity, setting time, seepage pressure, compressive strength, and bending strength of different materials in different groups were measured under dry and wet conditions.

\section{Materials and Methods}

2.1. Materials. An ordinary Portland cement P.O 42.5 with a fineness of $3100 \mathrm{~cm}^{2} / \mathrm{g}$, manufactured by China United Cement Corporation (Beijing, China), was used in the present study, and its chemical properties are listed in Table 1.

Polyacrylate emulsion, manufactured by Shanghai Sanrui Chemical Co., Ltd. (Shanghai, China), was herein used as a film-forming agent, whose solid content and glass state temperature are presented in Table 2.

Ordinary calcium carbonate $\left(\mathrm{CaCO}_{3}\right)$, purchased from Tuoyi New Materials Co., Ltd., with a mean particle size of $5 \mu \mathrm{m}$, was utilized as filling materials. Table 3 lists the chemical components and physical properties of $\mathrm{CaCO}_{3}$.

Hydroxyethyl methyl cellulose (HEMC), purchased from Hercules-Tianpu Chemical Co., Ltd. (Zhangjiagang, China), was selected as a tackifier. HEMC solution with a mass fraction of $2 \%$ is a water-soluble white powder with a particle size of below $150 \mu \mathrm{m}$ and a viscosity of $70000 \mathrm{MPa} \cdot \mathrm{s}$ at $25^{\circ} \mathrm{C}$. Table 4 lists the chemical components and physical properties of HEMC.

It is noteworthy that all these materials met the standards of GB/T 8076-2008 and GB/T 50119-2003. The materials' component properties as listed in the tables were provided by the manufacturers. 
TABLE 1: Chemical compositions of cement (unit: \%).

\begin{tabular}{lcccrr}
\hline $\mathrm{SiO}_{2}$ & $\mathrm{AI}_{2} \mathrm{O}_{3}$ & $\mathrm{Fe}_{2} \mathrm{O}_{3}$ & $\mathrm{CaO}$ & $\mathrm{MgO}$ & $\mathrm{SO}_{3}$ \\
\hline 19.5 & 6.45 & 3.08 & 57.57 & 1.21 & 2.01 \\
\hline
\end{tabular}

TABLE 2: Emulsion performance parameters.

\begin{tabular}{|c|c|c|c|c|c|}
\hline $\operatorname{Tg}\left({ }^{\circ} \mathrm{C}\right)$ & $\mathrm{pH}$ & Exterior & Content of solid substances (\%) & Viscosity $\left(25^{\circ} \mathrm{C}\right)(\mathrm{MPa} \cdot \mathrm{s})$ & Electric potential \\
\hline 5 & $6.5-7.5$ & White emulsion & $42-44$ & $>300$ & Negative \\
\hline
\end{tabular}

TABle 3: Chemical composition and physical properties of the filler.

\begin{tabular}{lcccccc}
\hline $\mathrm{CaCO}_{3}(\%)$ & $\mathrm{SiO}_{2}(\%)$ & $\mathrm{AL}_{2} \mathrm{O}_{3}(\%)$ & $\mathrm{Fe}_{2} \mathrm{O}_{3}(\%)$ & $\mathrm{Na}_{2} \mathrm{O}(\%)$ & Mean particle size & Density \\
\hline 97.1 & 0.63 & 0.22 & 0.11 & 0.03 & $5.7 \mu \mathrm{m}$ & $2.71 \mathrm{~g} / \mathrm{cm}^{3}$ \\
\hline
\end{tabular}

TABLE 4: Tackifier composition parameters.

\begin{tabular}{lccc}
\hline Main components & Exterior & Density $\left(\mathrm{kg} / \mathrm{m}^{3}\right)$ & \\
\hline Hypromellose & White powder & 500 & $\mathrm{pH}$ \\
\hline
\end{tabular}

The experimental additives mainly included fibers, a setting accelerator, a defoamer, and a dispersant. These additives were wholly used for facilitating the enhancement of film-forming agents or the improvement of performance of gel materials $[56,57]$, and thus were not listed as factors influencing testing.

Polypropylene fibers manufactured by Tai'an Tongban Fiber Co., Ltd., were used as the synthetic fibers in this study, which met the standard of GB/T21120-2007 and possessed extremely high acid/alkali stability and low-temperature resistance. Table 5 lists the physical properties of fibers.

The accelerator, defoamer, and dispersant, as the technical indicators listed in Table 6, were mixed by tap water.

Similarly, the specific properties of the materials as listed in tables were provided by manufacturers.

2.2. Mixture Proportions. With fixing $\mathrm{P} / \mathrm{C}=10 \%$ and changing $\mathrm{W} / \mathrm{C}$ (for convenience, $\mathrm{P}$ is the polymer, $\mathrm{C}$ is the cement, $\mathrm{W}$ is the water, $\mathrm{F}$ is the filler, and $\mathrm{T}$ is the tackifier), the materials with a viscosity of $500-7000 \mathrm{MPa} \cdot \mathrm{s}$ were prepared for investigating their ability to spray. At an interval of $500 \mathrm{MPa} \cdot \mathrm{s}, 14$ groups of materials were totally prepared.

The materials were optimized through Taguchi method experiments. Based on results of previously conducted studies [50, 53-55], a four-component experiment was designed, and the levels of different factors are mentioned in Table 7 . The added fibers occupied $0.5 \%$ in volume fraction. The added setting accelerator was $4 \%$ of the cement mass. Besides, the defoamer and the dispersant with the rate of equally $0.2 \%$ of cement mass were added. Table 8 lists the detailed addition ratios of 16 groups of experiments.

\subsection{Experimental Methods}

2.3.1. Preparation of Test Specimens. The specimens were prepared and then underwent bending and compressive tests according to the Chinese standards of GB/T 176711999 [58] and DL/T5126-2001 [59]. In order to reduce the introduction of bubbles, the polymer was added to water before stirring; then, the defoamer was added and stirred, and eventually, the setting accelerator was added. In the next step, cement and fibers were mixed and scattered; after that, the liquid was poured and mixed [60]. Using a hand stirrer, the mixture was stirred clockwise and counterclockwise at low velocities [1]. After mixing for $3 \mathrm{~min}$, the mixture was rapidly placed in a cuboid mould. Regarding the preparation process, TSL materials were first poured into the middle of the mould, and the gaps on the two ends were filled; then, the mould was placed on the shaking table and shook for compaction, as shown in Figure 2(a); after $24 \mathrm{~h}$, the mould was dismantled for curing.

Figure 2(b) displays the specimens in the bonding experiment, which were prepared through spraying. Because of the cementation influence of TSL materials on the coal surface, the bond fracture occurred in the coal matrix, and thus bond strength cannot be counted. Accordingly, the plastic template with a thickness of $5 \mathrm{~mm}$ was overlaid on the granite slate (see granite roughness in Figure $2(\mathrm{~d})$, which could reduce the damages to the bonding strength between materials and the matrix surface caused by mechanical coring after large-scale spraying [14]. After being soaked for $30 \mathrm{~min}$, the marble was taken out. The water spots on the wall surface were retained for simulating the wet tunnel or the tunnel surface washed by a hydraulic giant [61]. Next, spraying was performed to measure the bonding strength (X-Wet) on the wet wall surface. The air pressure for a spray gun and the spraying distance were set to $0.6 \mathrm{MPa}$ and $1 \mathrm{~m}$, respectively. After the spraying was finished, the material overflowing the mold was struck off by the scraper to control the depth. The mould was dismantled after $24 \mathrm{~h}$ for curing. 
TABle 5: Physical properties of polypropylene fibers.

\begin{tabular}{lccccc}
\hline Type & Cross section & Equivalent diameter $(\mu \mathrm{m})$ & Length $(\mathrm{mm})$ & Elastic modulus $(\mathrm{MPa})$ & Tensile strength $(\mathrm{MPa})$ \\
\hline Monofilament & Circle & $30-40$ & 6 & $\geq 3850$ & $\geq 500$ \\
\hline
\end{tabular}

TAвLE 6: Technical indicators of the accelerator, defoamer, and dispersant.

\begin{tabular}{|c|c|c|c|c|c|c|}
\hline \multirow{2}{*}{ Type } & \multirow{2}{*}{ Name } & \multirow{2}{*}{ Main components } & \multirow{2}{*}{ Density $\left(\mathrm{kg} / \mathrm{m}^{3}\right)$} & \multirow{2}{*}{$\mathrm{pH}$} & \multicolumn{2}{|c|}{ Setting time (min) } \\
\hline & & & & & Initial & Final \\
\hline Accelerator & WT-N1 & Aluminum sulfate & 1350 & 6 & $2-3$ & $7-9$ \\
\hline Defoamer & DF-110D & Acetylene glycol & 990 & 7.0 & - & - \\
\hline Dispersant & OT-75 & Dioctyl sodium succinate & 1240 & 7.5 & - & - \\
\hline
\end{tabular}

TABLe 7: Experiment factor level table.

\begin{tabular}{lcccc}
\hline Factor & W/C (\%) & P/C (\%) & F/C (\%) & T/C (\%) \\
\hline Level 1 & 40 & 2 & 1 & 0.2 \\
Level 2 & 45 & 6 & 3 & 0.4 \\
Level 3 & 50 & 10 & 5 & 0.6 \\
Level 4 & 55 & 14 & 7 & 0.8 \\
\hline
\end{tabular}

TABLE 8: Detailed ratio of each substance in the test.

\begin{tabular}{|c|c|c|c|c|}
\hline \multirow{2}{*}{ Experimental no. } & \multicolumn{4}{|c|}{ Variable } \\
\hline & W/C (\%) & $\mathrm{P} / \mathrm{C}(\%)$ & $\mathrm{F} / \mathrm{C}(\%)$ & $\mathrm{T} / \mathrm{C}(\%)$ \\
\hline 1 & 40 & 2 & 1 & 0.2 \\
\hline 2 & 40 & 6 & 3 & 0.4 \\
\hline 3 & 40 & 10 & 5 & 0.6 \\
\hline 4 & 40 & 14 & 7 & 0.8 \\
\hline 5 & 45 & 2 & 3 & 0.6 \\
\hline 6 & 45 & 6 & 1 & 0.8 \\
\hline 7 & 45 & 10 & 7 & 0.2 \\
\hline 8 & 45 & 14 & 5 & 0.4 \\
\hline 9 & 50 & 2 & 5 & 0.8 \\
\hline 10 & 50 & 6 & 7 & 0.6 \\
\hline 11 & 50 & 10 & 1 & 0.4 \\
\hline 12 & 50 & 14 & 3 & 0.2 \\
\hline 13 & 55 & 2 & 7 & 0.4 \\
\hline 14 & 55 & 6 & 5 & 0.2 \\
\hline 15 & 55 & 10 & 3 & 0.8 \\
\hline 16 & 55 & 14 & 1 & 0.6 \\
\hline
\end{tabular}

The sealing properties were measured by an SS-1.5 digital-readout penetrator. During the experiments, $400 \mathrm{~g}$ cement, $1200 \mathrm{~g}$ sand, and $240 \mathrm{~g}$ water were mixed to prepare the permeable mortar bed (Figure 2(c)) [62]. The mortar bed exhibited uniform permeable capability (i.e., dropped water can be oozed after $30 \mathrm{~min}$ under $0.2 \mathrm{MPa}$ ). TSL material with a thickness of $5 \mathrm{~mm}$ was sprayed on the mortar bed in a vacuum drying oven. Each group included 3 specimens (Figure 2(f)). After curing for 3 days, the impervious performance of the mortar was tested.

The specimen underwent standard curing. After the mould was dismantled, the specimen was placed into a constant-temperature and constant-humidity standard curing box (Figure $2(\mathrm{e})$ ) for $28 \mathrm{~d}$. The relative humidity and the temperature were fixed at $97 \%$ and $20 \pm 3^{\circ} \mathrm{C}$, respectively.
2.3.2. Ability to Spray. A high-pressure pump and an integrated spray gun were employed for the jet test, and the layout of equipment is shown in Figure 3. In this experiment, 14 groups of materials were tested by the spray gun. The ability to spray was evaluated by the adhesion effect.

2.3.3. Measurement of Fluidity. In the present study, the flowability of TSL materials was measured by viscosity. The viscosity was measured by the NDJ-79 Rotational Viscometer (Figure 4(a)).

2.3.4. Measurement of Setting Time. According to the Chinese standard of GB/T 1346-2011, the setting time was measured by a Vicat apparatus (Figure 4(b)) [63, 64]. 


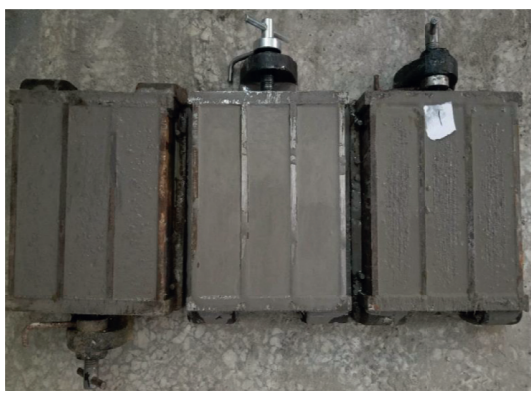

(a)

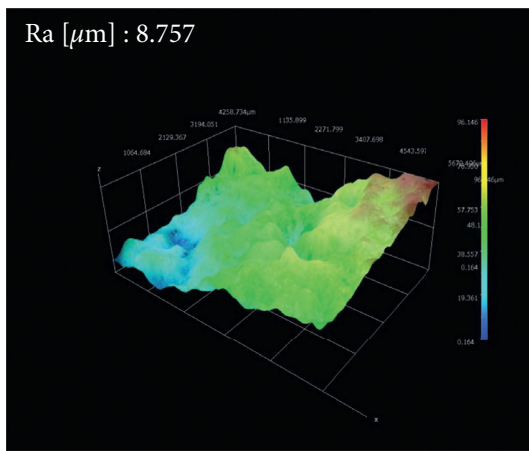

(d)

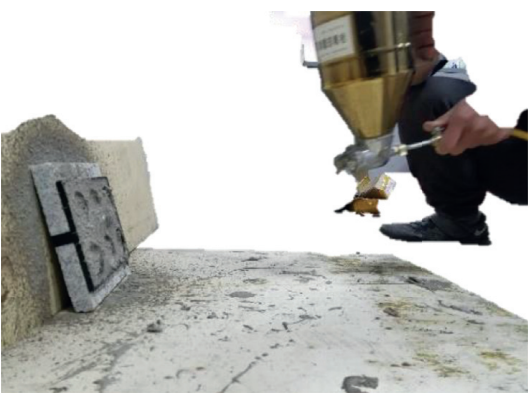

(b)

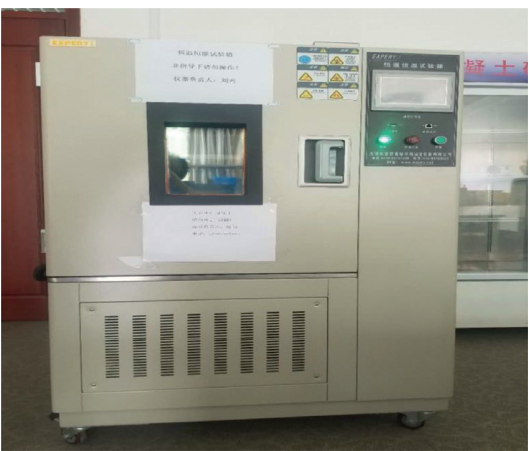

(e)

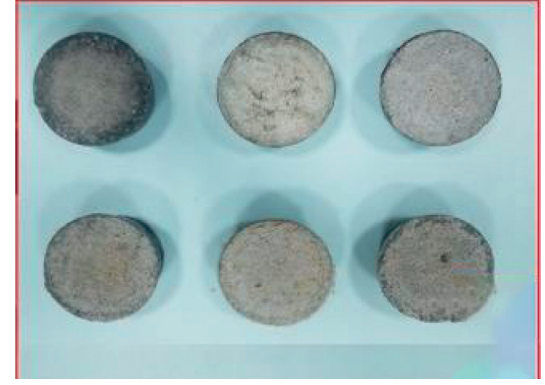

(c)

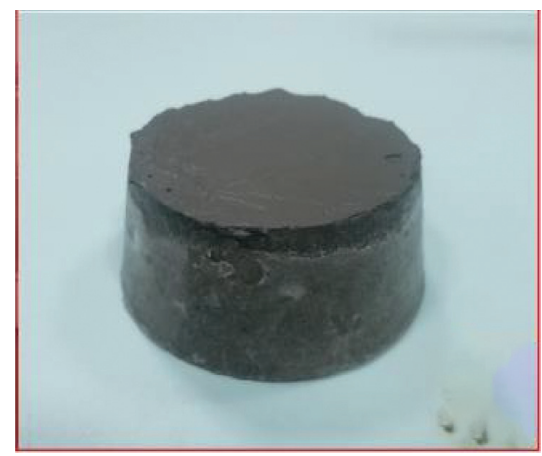

(f)

FIGURE 2: Sample preparation process. (a) Experimental rectangular test piece. (b) Bond test piece making. (c) Permeable substrate. (d) Surface roughness of bonded substrates. (e) Test piece maintenance box. (f) Penetration test block.

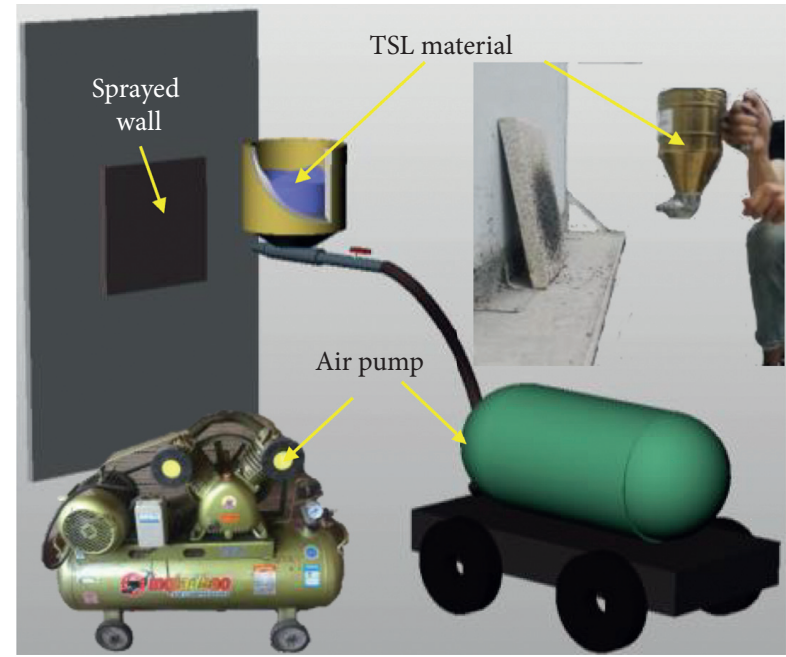

FIGURE 3: Jet experimental platform.

2.3.5. Measurement of Sealing Properties. TSL sealing properties were tested by a permeameter (Figure 4(c)) [65]. TSL material with a thickness of $5 \mathrm{~mm}$ was sprayed on the mortar bed. After drying, the test piece was put into the instrument and then was gradually pressurized (the water pressure starts from $0.2 \mathrm{MPa}$ and increases by $1 \mathrm{MPa}$ per hour). Each group included 3 specimens. After curing for 3 days, the impervious performance of the mortar was tested. In each group, three specimens were measured and averaged.
2.3.6. Mechanical Performance Measurement. The bending and compressive strengths were measured in accordance with the Chinese standard of GB/T 17671-1999 [58]. The test is shown in Figures 4(e) and 4(f).

2.3.7. Measurement of Bonding Strength. The bonding strength was measured by an adhesive-strength tester (Figure 4(d)) [14]. Before testing, a disk was bonded to the materials via an epoxy adhesion and underwent $48 \mathrm{~h}$ curing at $25^{\circ} \mathrm{C}$. The bonding strength was determined by dividing the pull-out force by the adhesive area [66]:

$$
\sigma=\frac{P}{\pi a^{2}}
$$

where $\sigma$ is the bonding strength, $P$ is the maximum pulling force, and $a$ is the radius of the disk.

2.3.8. Microscopic Observation. The bonding interface was observed using a Leica Digital Microscopy (DVM5000HD) $3 \mathrm{D}$ microscope (Figure $4(\mathrm{~g})$ ). The fibers in the TSL were observed under a MIRA3 LMH scanning electron microscope (Figure 4(h)).

\section{Results and Discussion}

3.1. Results for Jet Test. Moderate viscosity can ensure that the materials permeate into cracks of rocks and contribute to strengthening and favorable wall hanging. In the present study, by observing the difficulty in spraying and the surface spraying performance, the adhesive conditions of TSL 


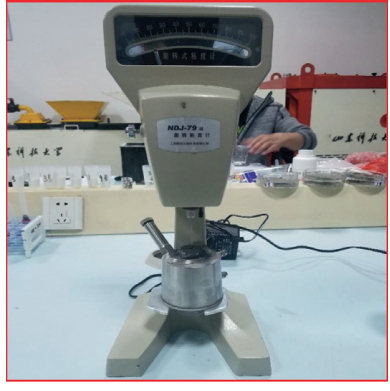

(a)

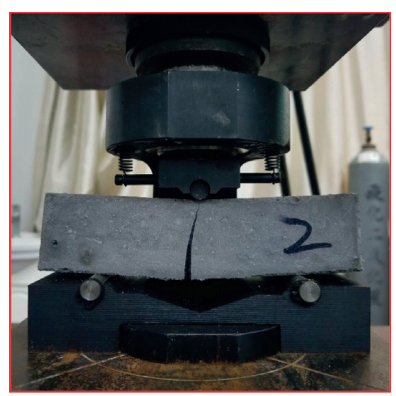

(e)

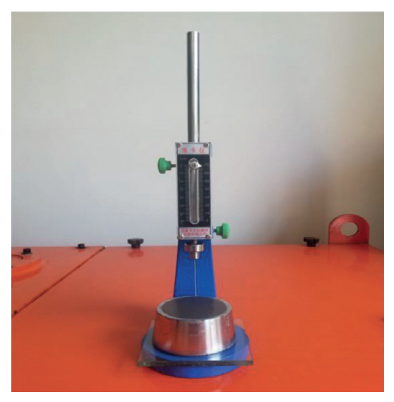

(b)

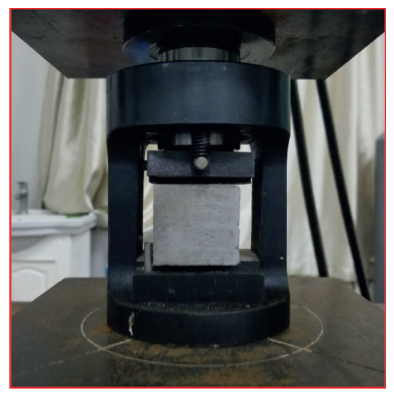

(f)

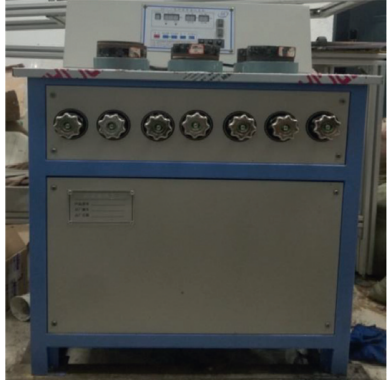

(c)

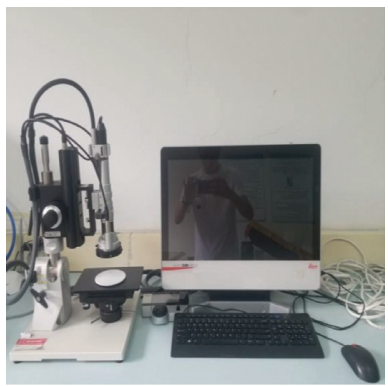

$(\mathrm{g})$

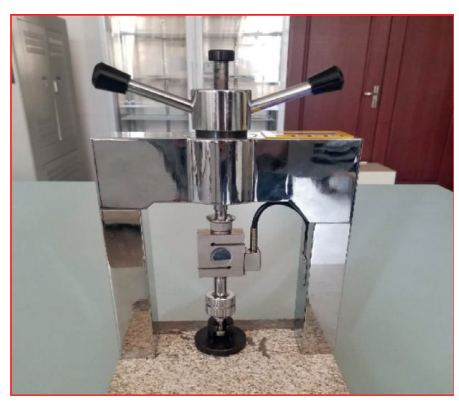

(d)

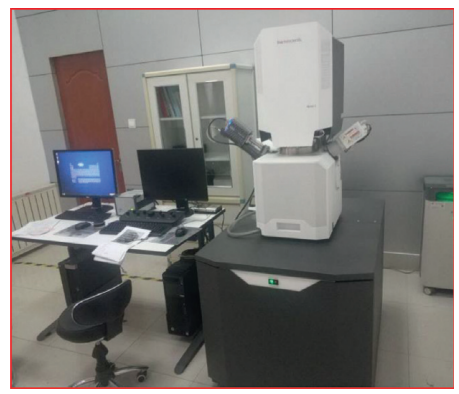

(h)

Figure 4: Experimental test process. (a) Viscosity test. (b) Setting time test. (c) Permeability test. (d) Bond test. (e) Three-point bending test. (f) Compressive strength test. (g) Microscopic observation. (h) SEM test.

sealing materials were classified into three types, as shown in Figures 5(a)-5(c), respectively.

Within a viscosity of $0-1500 \mathrm{MPa} \cdot \mathrm{s}$, the materials can be smoothly ejected out by the spray gun, as illustrated in Figure 5(a). At a low viscosity, the materials can be sprayed in mist flow, which cannot effectively hit the wall; accordingly, a great number of bubbles existed between the spray layer, thereby leading to spraying defects. Meanwhile, after spraying, materials flowed downward along the wall and failed to form a thick spray layer on the wall surface. Within a moderate viscosity range of $1500-6000 \mathrm{MPa} \cdot \mathrm{s}$, the materials can be smoothly ejected out by the spray gun in the form of small droplets, as shown in Figure 5(b). Under this condition, the sprayed small droplets can be uniformly attached to the wall surface. Additionally, regarding strong bonding force, a stable spray layer with a thickness of $10 \mathrm{~mm}$ was formed. As viscosity increased to 6000-9500 MPa.s, the materials can hardly be ejected out (Figure 5(c)). At a high viscosity, the materials were aggregated around the nozzle, then, sprayed in a strip pattern, and eventually moved downward under gravity. Due to the aggregation of highviscosity materials, the materials cannot effectively hit the wall surface, easily resulting in defects in spraying. Therefore, such a high viscosity range is not appropriate for spraying operation. In actual spraying process, the materials with a viscosity range of $1500-6000 \mathrm{MPa} \cdot \mathrm{s}$ can achieve favorable wall-hanging performance.

3.2. Results for Taguchi Method. The results of Taguchi method are given in Table 9.

As listed in Table 9, the viscosities of the specimens in all groups ranged from 620 to $9500 \mathrm{MPa} \cdot \mathrm{s}$. The abovementioned results demonstrated that the materials with a viscosity range of $1500-1600 \mathrm{MPa} \cdot \mathrm{s}$ were highly appropriate for spraying. Moreover, when the setting time ranged from the initial setting time $(40-85 \mathrm{~min})$ to the final setting time (247-345 $\mathrm{min}$ ) and the seepage pressure was within a range of $0.40-0.72 \mathrm{MPa}$, a shorter setting time was favorable for further construction. When the bending strength ranged from 2.64 to $0.68 \mathrm{MPa}$ and the compressive strength ranged from 28.73 to $5.41 \mathrm{MPa}$, the materials exhibited superior performance under a high bending strength. The materials with a compressive strength of below $10 \mathrm{MPa}$ cannot effectively fill in the cracks [29, 67]. The ranges of bonding strength under dry and wet conditions were $0.376-2.233 \mathrm{MPa}$ and $0.704-2.609 \mathrm{MPa}$, respectively.

3.3. Discussion for Taguchi Method. The effects of main factors on the performance of materials were examined via the Taguchi method. The influence rules of various factors were concluded by analyzing the experimental data using the related software, and the reasons were explored.

According to the analysis results listed in Table 10, the factors can be ranked in terms of degree of effectiveness. Regarding the influences on the viscosity of TSL materials, the following order is recommended: T/C $>\mathrm{W} / \mathrm{C}>\mathrm{P} / \mathrm{C}>\mathrm{F} /$ $\mathrm{C}$; with respect to the effects on the initial setting time, the following order is acceptable: W/C $>\mathrm{P} / \mathrm{C}>\mathrm{T} / \mathrm{C}>\mathrm{F} / \mathrm{C}$; regarding the influence on the final setting time, $\mathrm{P} / \mathrm{C}>\mathrm{W} / \mathrm{C}$ is recommended; with respect to the effect on bending strength, the following order is advised: $\mathrm{P} / \mathrm{C}>\mathrm{W} / \mathrm{C}>\mathrm{T} /$ $\mathrm{C}>\mathrm{F} / \mathrm{C}$; regarding the effect on compressive strength, $\mathrm{P} /$ $\mathrm{C}>\mathrm{W} / \mathrm{C}>\mathrm{T} / \mathrm{C}>\mathrm{F} / \mathrm{C}$ would be recommended; regarding the effect on the bonding strength under dry condition, the 

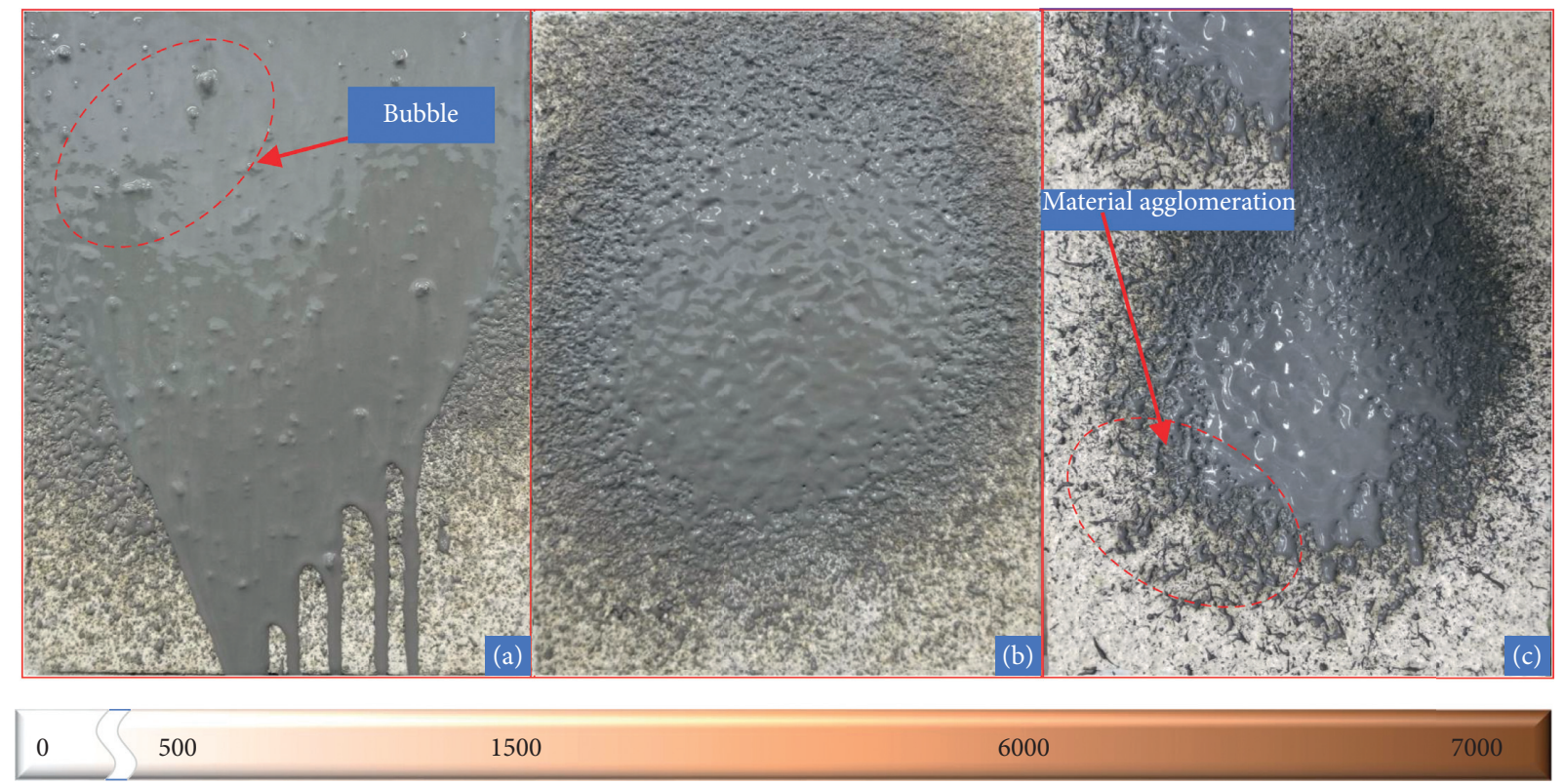

Viscosity $(\mathrm{mPa} \cdot \mathrm{s})$

Figure 5: Typical spray effect diagram.

TABLE 9: Test result statistics.

\begin{tabular}{|c|c|c|c|c|c|c|c|c|}
\hline $\begin{array}{l}\text { Experimental } \\
\text { no. }\end{array}$ & $\begin{array}{l}\text { Viscosity } \\
(\mathrm{MPa} \cdot \mathrm{s})\end{array}$ & \multicolumn{2}{|c|}{$\begin{array}{l}\text { Setting time } \\
\quad(\min )\end{array}$} & $\begin{array}{l}\text { Seepage pressure } \\
(\mathrm{MPa})\end{array}$ & $\begin{array}{l}\text { Flexural strength } \\
\qquad(\mathrm{MPa})\end{array}$ & $\begin{array}{l}\text { Compressive strength } \\
\qquad(\mathrm{MPa})\end{array}$ & $\begin{array}{c}\text { Bond } \\
\text { strength } \\
(\text { dry })(\mathrm{MPa})\end{array}$ & $\begin{array}{c}\text { Bond } \\
\text { strength } \\
\text { (wet) (MPa) }\end{array}$ \\
\hline 1 & 2200 & 40 & 247 & 0.41 & 1.30 & 26.05 & 0.418 & 1.247 \\
\hline 2 & 4200 & 41 & 255 & 0.67 & 1.71 & 20.91 & 0.581 & 2.113 \\
\hline 3 & 2000 & 50 & 273 & 0.71 & 1.30 & 12.14 & 0.376 & 1.111 \\
\hline 4 & 9500 & 53 & 295 & 0.67 & 0.68 & 5.92 & 0.668 & 0.833 \\
\hline 5 & 4700 & 39 & 260 & 0.50 & 1.78 & 24.91 & 0.683 & 1.137 \\
\hline 6 & 6000 & 52 & 316 & 0.66 & 2.64 & 26.89 & 1.387 & 2.609 \\
\hline 7 & 1600 & 50 & 295 & 0.72 & 1.71 & 15.11 & 0.766 & 1.574 \\
\hline 8 & 3500 & 56 & 295 & 0.69 & 0.76 & 7.14 & 1.585 & 1.276 \\
\hline 9 & 4000 & 53 & 292 & 0.42 & 1.90 & 28.73 & 0.719 & 0.813 \\
\hline 10 & 3500 & 49 & 295 & 0.55 & 1.97 & 21.23 & 0.908 & 0.704 \\
\hline 11 & 2400 & 59 & 315 & 0.65 & 1.25 & 10.34 & 2.021 & 2.427 \\
\hline 12 & 620 & 56 & 330 & 0.53 & 0.90 & 5.41 & 2.233 & 1.104 \\
\hline 13 & 1400 & 56 & 288 & 0.41 & 1.90 & 21.52 & 0.942 & 1.055 \\
\hline 14 & 1000 & 62 & 275 & 0.40 & 2.08 & 18.82 & 1.859 & 2.542 \\
\hline 15 & 2500 & 81 & 337 & 0.50 & 1.56 & 11.83 & 0.739 & 0.848 \\
\hline 16 & 2600 & 85 & 345 & 0.48 & 0.80 & 5.85 & 1.258 & 2.037 \\
\hline
\end{tabular}

following order is recommended: W/C $>\mathrm{P} / \mathrm{C}>\mathrm{T} / \mathrm{C}>\mathrm{F} / \mathrm{C}$; with respect to the effect on the bonding strength under wet condition, $\mathrm{F} / \mathrm{C}>\mathrm{P} / \mathrm{C}>\mathrm{T} / \mathrm{C}>\mathrm{W} / \mathrm{C}$ is recommended.

3.3.1. Fluidity. In the present study, the flowability of TSL materials was measured by viscosity. The abovementioned findings revealed that $\mathrm{T} / \mathrm{C}$ and $\mathrm{W} / \mathrm{C}$ were two main factors that significantly affected viscosity. The tackifier was then added for controlling viscosity of TSL materials, as well as achieving a balance between wall-attachment sagging and difficulty in spraying.
Figure 6 displays the effects of various factors on viscosity. The viscosity of TSL materials linearly dropped with the increase in $\mathrm{W} / \mathrm{C}$, which can be attributed to a tight correlation between material flowability and the particles' surface performance [68]. The cement particles were wrapped by water molecules, which reduced the friction among particles and played a lubricating role among the particles. Meanwhile, a significant correlation between W/C and P/C could be observed, as shown in Figure 7.

It also was uncovered that the viscosity of TSL materials increased constantly with the increase in $\mathrm{T} / \mathrm{C}$ from $0.2 \%$ to $0.8 \%$. In addition, the viscosity rose more rapidly with $\mathrm{T} / \mathrm{C}$ at 
TABle 10: Range statistics.

\begin{tabular}{|c|c|c|c|c|c|}
\hline & & $\mathrm{W} / \mathrm{C}$ & $\mathrm{P} / \mathrm{C}$ & $\mathrm{F} / \mathrm{C}$ & $\mathrm{T} / \mathrm{C}$ \\
\hline \multicolumn{2}{|l|}{ Viscosity $(\mathrm{MPa} \cdot \mathrm{s})$} & 2600 & 1930 & 1375 & 4145 \\
\hline \multirow{2}{*}{ Setting time $(\min )$} & Initial & 24.88 & 15.62 & 6.94 & 7.63 \\
\hline & Final & 43.75 & 44.50 & 22.10 & 23.25 \\
\hline Seepage pressure $(\mathrm{MPa})$ & & 0.25 & 0.22 & 0.05 & 0.05 \\
\hline Bending strength (MPa) & & 0.573 & 1.420 & 0.152 & 0.291 \\
\hline Compressive strength ( $\mathrm{MPa})$ & & 4.009 & 19.222 & 1.519 & 3.365 \\
\hline \multirow{2}{*}{ Bond strength (MPa) } & Dry & 0.959 & 0.746 & 0.450 & 0.513 \\
\hline & Wet & 0.387 & 0.929 & 1.039 & 0.471 \\
\hline
\end{tabular}

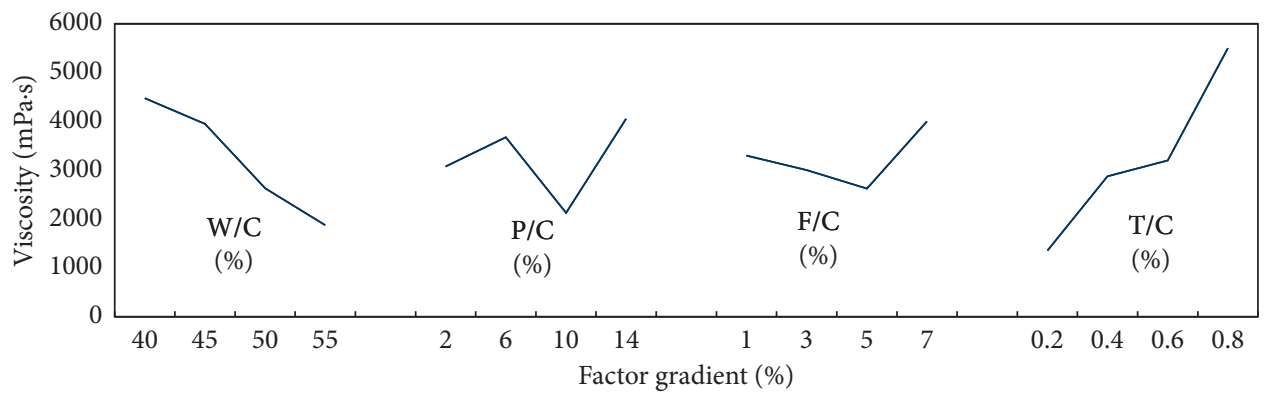

FIgURE 6: Viscosity factor influence diagram.

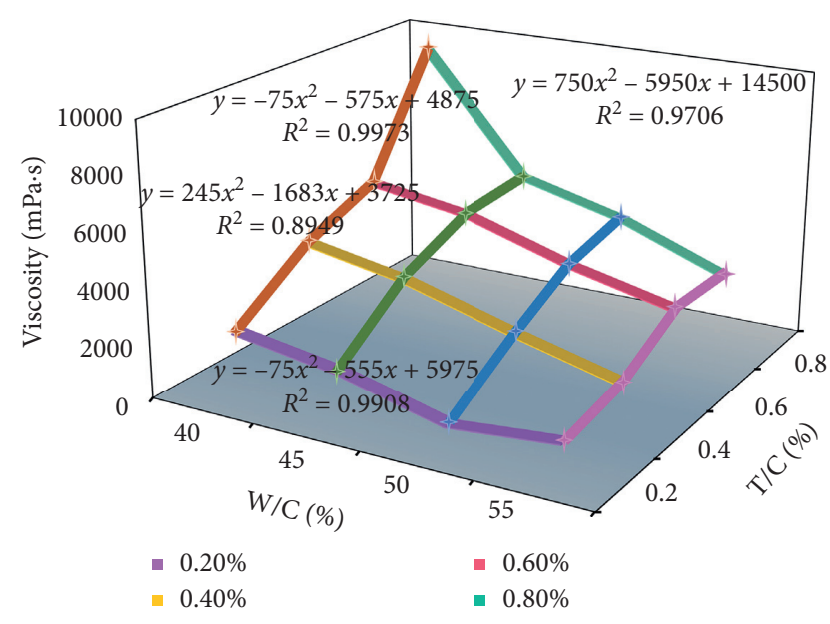

Figure 7: W/C interaction with T/C.

a lower $\mathrm{W} / \mathrm{C}$. When $\mathrm{W} / \mathrm{C}=40 \%$, the viscosity elevated by $331.8 \%$; when $\mathrm{W} / \mathrm{C}=45 \%$, the viscosity increased by $212.5 \%$; when $\mathrm{W} / \mathrm{C}=50 \%$, the viscosity rose by $201.1 \%$; and when $\mathrm{W} /$ $\mathrm{C}=55 \%$, the viscosity elevated by $150 \%$. The increase in viscosity when $\mathrm{W} / \mathrm{C}=55 \%$ was reduced by $54.8 \%$ compared with the condition when $\mathrm{W} / \mathrm{C}=40 \%$. Accordingly, it can be concluded that dilution of water in the TSL materials remarkably reduced the increase in viscosity by the addition of a tackifier.

As $\mathrm{P} / \mathrm{C}$ increased, the viscosity of TSL materials first increased slightly, and then decreased, and eventually elevated. This is due to the fact that an electrical adsorption between polyacrylate and cement particles led to the accumulation of cement particles, in addition to a decline in flowability [69]. However, as P/C further increased, cement particles were adsorbed by a great amount of polyacrylate and became negatively charged, thereby producing electrical repulsion and reducing the viscosity. Meanwhile, free water molecules were released. A small amount of unadsorbed polyacrylate played a role of the lubricator, which further reduced the viscosity. Nevertheless, as the content of free polyacrylate in the material increased, the thickening-undershear properties became further obvious since polyacrylate is a kind of macromolecular polymer, thereby leading to the constant increase in viscosity [48].

As depicted in Figure 7, the viscosity of TSL materials initially decreased, and then increased with the elevation of F/C. Since fine filler materials adequately filled in the gap among cement particles, the viscosity was reduced [70]. The filling materials with a larger specific area adsorbed a greater amount of free water, and the reduction of free water among particles led to the increase in viscosity [71]. The addition of calcium carbonate enhanced the bonding force and the attraction and friction among cement particles, which led to the increase in viscosity [72]. These findings were well consistent with Nehdi's outcome [70].

The viscosity also increased gradually with the increase in T/C. After the addition of hydroxypropyl methyl cellulose (HPMC), oxygen atoms on the hydroxyls and ether bonds can bond with water molecules to form a hydrogen bond, and therefore the content of free water dropped; i.e., HPMC may play the role of increasing viscosity and holding water [73]. Meanwhile, the addition of HPMC can form porous networks with a diameter of approximately $50-250 \mu \mathrm{m}$. According to the Newton inner friction law, reduction of pore diameter slowed down liquid-phase transition process and enhanced capillary effect, and free water molecules filled 
in the porous structures. Therefore, some free water was preserved in large unsaturated porous space [74]. The decrease in free-moving water molecules increased the viscosity of the material.

3.3.2. Setting Time. The setting time of materials can be used for describing the related curing speed. A rapid condensation can enhance the efficiency of tunnel construction, shorten the construction period, and reduce expenses. As presented in Table 10, among all specimens, the initial setting time ranged from 39 to $85 \mathrm{~min}$, while the final setting time ranged from 247 to $345 \mathrm{~min}$.

Figure 8 shows the effects of various factors on the initial setting time. Apparently, with the increase in $\mathrm{W} / \mathrm{C}$, the setting time increased constantly. The increase in $\mathrm{W} / \mathrm{C}$ expanded the gap among cement particles. Accordingly, the overall structure became less compact, and the structural network can be hardly formed.

With the increase in $\mathrm{P} / \mathrm{C}$, the initial setting time of TSL materials increased constantly. According to the Ohama model, the added polymer was attached to the cement particles, which hindered the hydration action and prolonged the initial setting time.

The initial setting time dropped slightly with the increase in $\mathrm{F} / \mathrm{C}$, which can be attributed to the water-absorbing capacity of TSL materials. The increase in the filler content reduced the $\mathrm{W} / \mathrm{C}$ ratio in the materials and shortened the setting time of the TSL materials. The ratios of F/C and T/C were $27 \%$ and $30 \%$, respectively, suggesting slight effects on the materials.

Various factors imposed similar influences on the final setting time to the initial setting time. Two differences are described in the following.

Firstly, the effect of $\mathrm{P} / \mathrm{C}$ on the final setting time was enhanced. The ratio of $\mathrm{P} / \mathrm{C}$ exceeded that of $\mathrm{W} / \mathrm{C}$. This is due to the fact that the polymer exhibited a great film-forming rate on the specimen surface.

Secondly, with the increase in F/C, the initial setting time first decreased and then increased. On the one hand, the addition of filling materials can absorb more water molecules and enhance the compact degree among cement particles, thereby shortening the setting time [71]; on the other hand, the addition of filling materials can decrease the proportion of cement and prolong the setting time. At a low proportion, the filling materials exhibited remarkable water absorption and setting promotion effect, and the setting time was shortened. As filling materials were further added, the decrease in the cement content led to the reduction of cemented materials and prolonged setting time as well.

3.3.3. Seepage Pressures. Impervious performance is also a main measurement index of TSL materials. TSL with excellent impervious performance can effectively seal the tunnel, prevent water seepage, and avoid rock weathering. As mentioned in Table 10, the maximum and minimum seepage pressures of all specimens in different groups were 0.7 and $0.3 \mathrm{MPa}$, respectively. According to results of analysis, $\mathrm{W} / \mathrm{C}$ and $\mathrm{P} / \mathrm{C}$ are the main factors influencing TSL materials.

Figure 9 shows the effects of various factors on the impervious performance. With the increase in $\mathrm{W} / \mathrm{C}$, the seepage pressure dropped. Since the increase in water content led to a greater porosity after curing, water molecules more easily flowed through the materials and the seepage pressure constantly dropped.

With the increase in $\mathrm{P} / \mathrm{C}$, the content of polymer in the materials increased constantly. The polymer was adsorbed on the cement hydration products, and the formed films filled in a gap in the TSL materials. However, the constant increase in the polymer content highlighted the entraining effect, increased defects in the specimens, and reduced the seepage pressure.

With the increase in $\mathrm{F} / \mathrm{C}$, the seepage pressure slightly increased. Due to the limited filling ratio, the seepage pressure increased slightly. The seepage pressure first increased and then dropped with the elevation of T/C. The action mechanism was similar to the effect of the polymer. Overall, the ratios of F/C and T/C were only $20 \%$ of W/C, suggesting unobvious effects on the seepage pressure.

3.3.4. Flexural and Compressive Strengths. This study employed bending and compressive strengths for measuring the wedge and bearing-basket effects of TSL materials, so that the stress on the rock tip can be effectively reduced and the fell-off rocks with great mass can be held when the cracks were filled by TSL materials $[36,38]$. As listed in Table 10, the maximum and minimum bending strengths of all mixtures were 2.64 and $0.68 \mathrm{MPa}$, respectively, while the maximum and minimum compressive strengths were 28.73 and 5.41 $\mathrm{MPa}$, respectively.

As illustrated in Figure 10(a), with the increase in W/C, the bending strength first increased and then decreased. According to the Ohama model, the hydration of cement particles can be suppressed by polymer emulsion. Therefore, when $\mathrm{W} / \mathrm{C}=40 \%$, the TSL materials underwent incomplete hydration, and the bending and compressive strengths of TSL materials were insignificant [69]. As W/C elevated, the polymer was diluted by more water, thereby leading to further hydration of cement particles and greater strength. As W/C further increased, the proportion of gels in the TSL materials dropped, and therefore, the masses of crystals and gels in the TSL materials dropped and the bending strength was reduced as well.

With the increase in $\mathrm{P} / \mathrm{C}$, the bending strength of TSL materials first rose and then dropped. The reasons can be explained in the following. On the one hand, the low-content polymer can be adsorbed on the hydration products of the cement, so as to form films. Jin et al. found that the lowcontent polymer enhanced calcium hydroxide crystals and enhanced the bending strength of TSL materials [75]. Owing to a low content, the polymer imposed a slightly negative influence on the hydration of cement. As the content of acrylic acid increased, more carboxyl could be formed after the hydrolysis of carboxyl and ester groups in the polymer, which then were complicated with $\mathrm{Ca}$ ions in the solution 


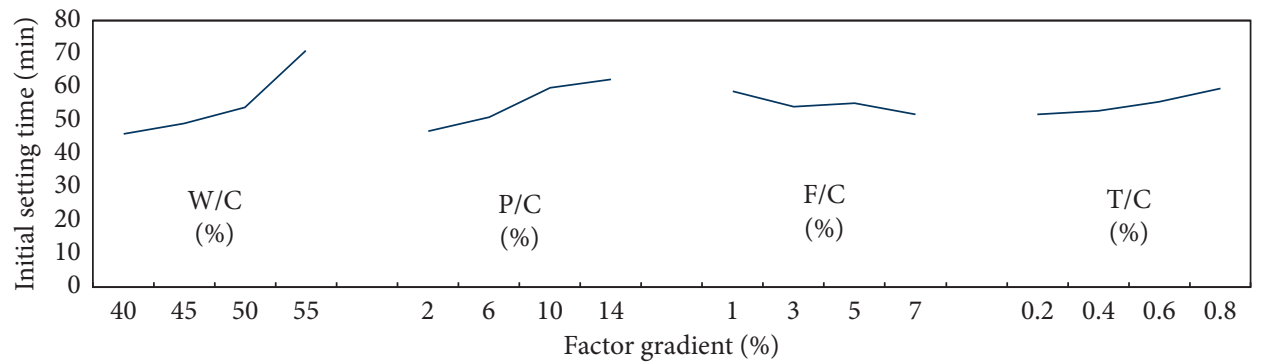

(a)

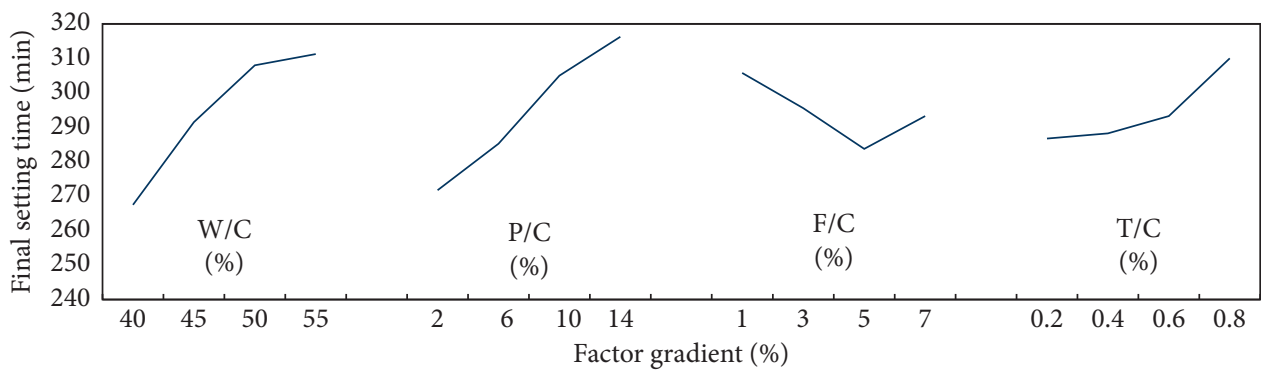

(b)

FIGURE 8: Setting time influence factor diagram. (a) Initial setting time factor influence diagram. (b) Final setting time factor influence diagram.

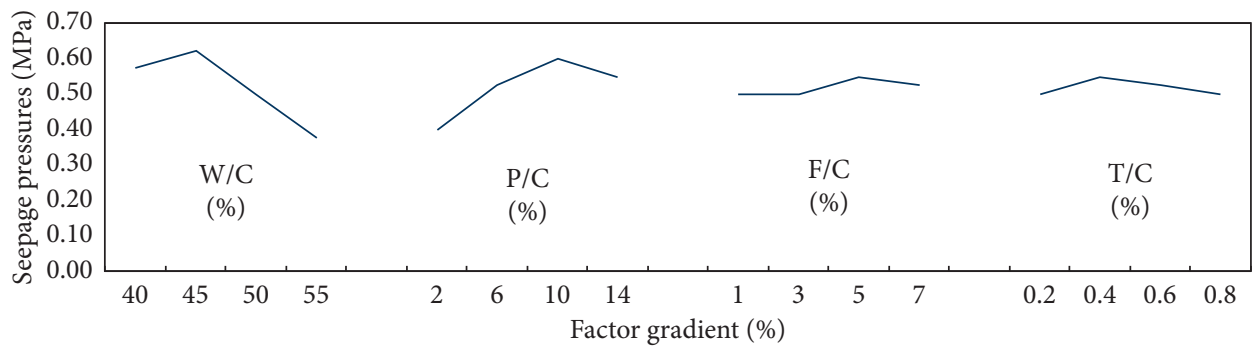

Figure 9: Osmotic pressure factor influence diagram.

and formed carboxylate. Accordingly, the ductility of TSL materials can be enhanced [54]. As the content of the polymer raised by $6-14 \%$, cement particles were wrapped by more polymers, and the hydration reaction was incomplete. The decrease in hydration products reduced the bending strength of TSL materials. Meanwhile, according to the Griffith theory of fracture, the bubbles were easily introduced after the addition of a high content of polymer, which also imposed negative impacts on overall compactness and microstructure [76], and these findings are similar to those reported by $\mathrm{Li}$ [77]. On the other hand, adding an appropriate amount of $\mathrm{P} / \mathrm{C}$ enhanced the bridge effect of fibers in the TSL materials. According to the images under scanning electron microscopy (SEM) (Figure 11), in contrast to the results without the addition of the polymer, adding the polymer optimized the interface structure between fibers and cement, filled in a gap between fibers and cement, and increased the area of the contact surface. Therefore, fibers and TSL materials were more tightly connected. Najm et al. drew similar conclusions [78]. However, after the addition of a great amount of polymer, an adhesive layer between fibers and cement became thicker. Ozturk and Tannant also pointed out that the bonding strength dropped at a thicker interface [66].

The bending and compressive strengths of TSL materials varied slightly with the increase in $\mathrm{F} / \mathrm{C}$, suggesting that the addition of filling materials imposed no significant effects. With the increase in $\mathrm{T} / \mathrm{C}$, both bending and compressive strengths slightly increased. Due to the addition of HEMC, $\mathrm{Ca}(\mathrm{OH})_{2}$ grew in multidirections, and as a result, the strength of materials was enhanced [79-81].

As expressed in Table 10, the corresponding ratios of $\mathrm{F} / \mathrm{C}$ and $\mathrm{T} / \mathrm{C}$ related to bending strength were 0.152 and 0.29 , respectively, which were $10.8 \%$ and $20.7 \%$ of the ratios of $\mathrm{P} /$ C. In other words, $\mathrm{F} / \mathrm{C}$ and $\mathrm{R} / \mathrm{C}$ imposed slight effects on bending strength.

As illustrated in Figure 10(b), compared with bending strength, the compressive strength exhibited a similar variation with $\mathrm{W} / \mathrm{C}$. The difference lies in that the compressive strength dropped steadily with the increase in $\mathrm{P} / \mathrm{C}$, which is consistent with the findings reported by Wang et al. [50]. On the one hand, based on freezing SEM images, Sakai and Sugita found that the compressive strength of the polymer was lower than that of cement [82]; after the addition of the 


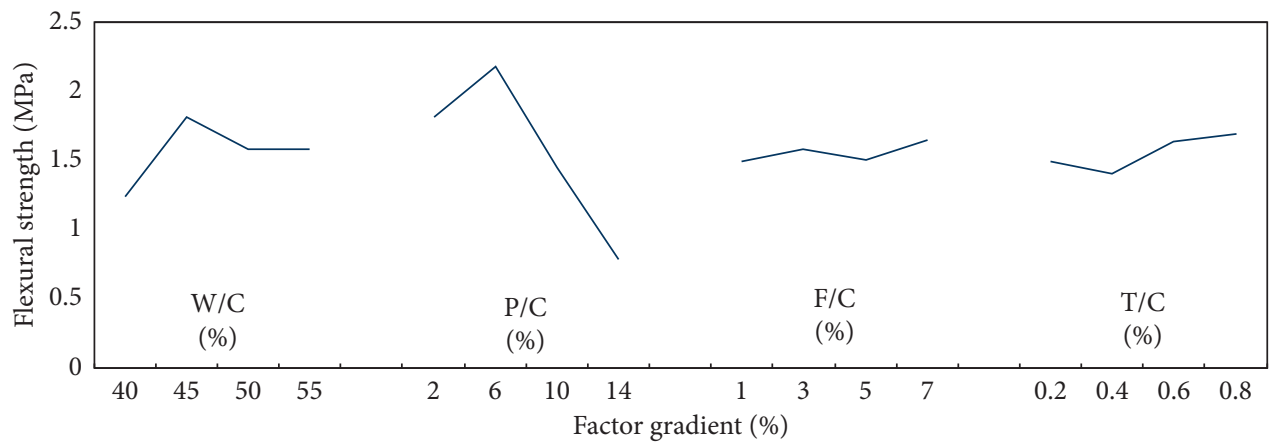

(a)

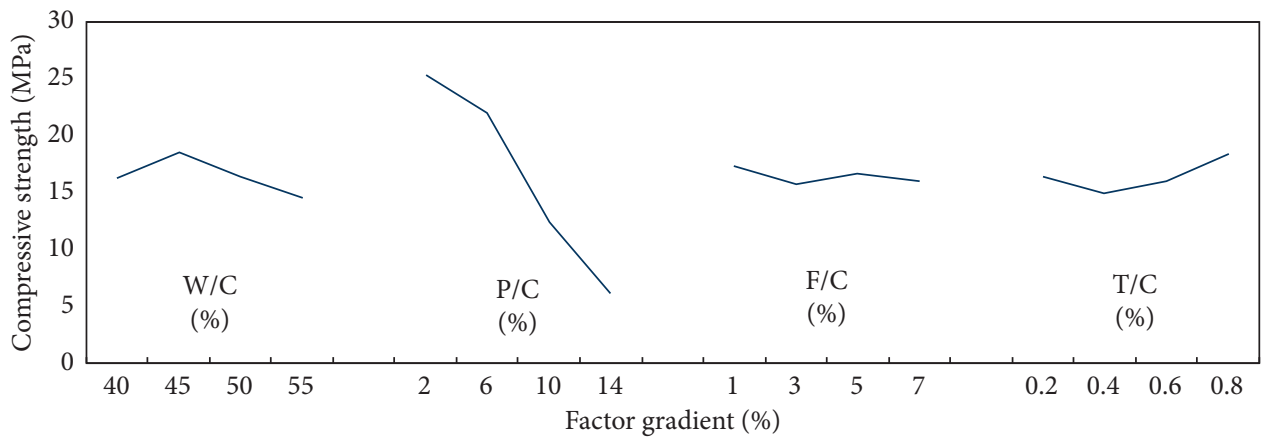

(b)

FIgURE 10: Influence factor diagram. (a) Flexural strength factor influence diagram. (b) Compression strength factor influence diagram.

polymer, the low-modulus polymer existed in the cement hydration products, which reduced the material's compressive strength. On the other hand, the added polymer was easily adsorbed on cement particles, which isolated the contact between cement particles and water, and led to insufficient cement hydration. The formed C-S-H gel reduced the compactness and the compressive strength of materials.

The corresponding ratios of $\mathrm{F} / \mathrm{C}$ and $\mathrm{T} / \mathrm{C}$ related to compressive strength were 1.519 and 3.365 , respectively, which were $8.9 \%$ and $17.5 \%$ of the ratios of $\mathrm{P} / \mathrm{C}$, suggesting insignificant influences.

The main factors influencing the materials exhibited no significant interaction.

3.3.5. Bond Strength. In addition, TSL's excellent adhesive performance greatly enhanced the interlocking effect between rocks and the performance as bearing baskets, thereby inhibiting the propagation of cracks. All of these made TSLs to significantly attract scholars' attention $[13,14]$. However, adhesion of TSL on the wet wall has been poorly investigated.

As shown in Table 10, the minimum and maximum bonding strengths on the dry wall were 0.376 and $2.233 \mathrm{MPa}$, respectively, while the minimum and maximum bonding strengths on the wet wall were 0.707 and $2.609 \mathrm{MPa}$, respectively. The results demonstrated that $\mathrm{W} / \mathrm{C}$ and $\mathrm{P} / \mathrm{C}$ were the main factors influencing the bonding strength on the dry wall surface.
The bonding strength of TSL materials was subjected to both bonding force and area [83]. According to results of bending and compressive strengths, the effect of hydration reached the optimal when $\mathrm{W} / \mathrm{C}=45 \%$; however, on the dry wall, the optimal bonding strength was achieved when W/ $\mathrm{C}=50 \%$. Since some water in the materials on the contact wall surface was absorbed by the dry rock wall, the hydration effect reached the optimal when W/C increased to 50\%; meanwhile, the optimal bonding force was attained. Furthermore, as W/C increased, the flowability of TSL materials increased, suggesting a superior penetration into cracks in rocks. Accordingly, the contact area with the wall increased and the material became more tightly bonded, leading to the increase in bonding strength. Figure 12 compares the bonding strengths of the specimens in the 11th group on both dry and wet wall surfaces. However, further increasing $\mathrm{W} / \mathrm{C}$ reduced the proportion of gel in the TSL materials and caused a decline in the bonding strength.

As illustrated in Figure 13(a), with the increase in P/C, the bonding strength on the dry wall surface first rose, then decreased, and eventually elevated. On the bonding surface, at a low level (2-6\%), P/C imposed a slight effect on the hydration of cement. Great mechanical occlusal force was generated during the hydration process of cement. Because of high bonding strength between the polymer and the wall surface [6], the polymer served as glue on the bonding surface, and the bonding strength increased steadily. As P/C increased to $6-10 \%$, an increasing amount of polymer was adsorbed to the rock surface, which also increased the bonding strength. However, the polymer was separated out 


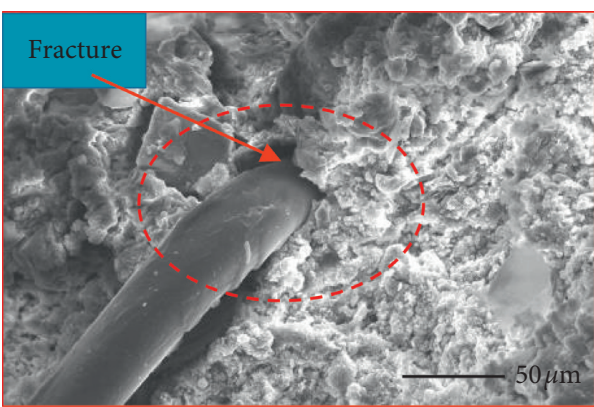

(a)

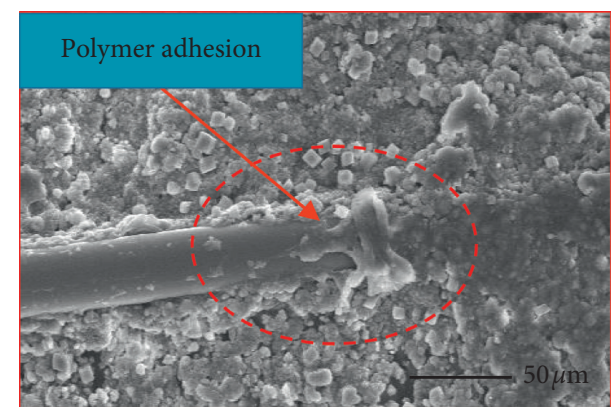

(b)

Figure 11: Material fiber attachment. (a) No polymer. (b) Polymer materials.

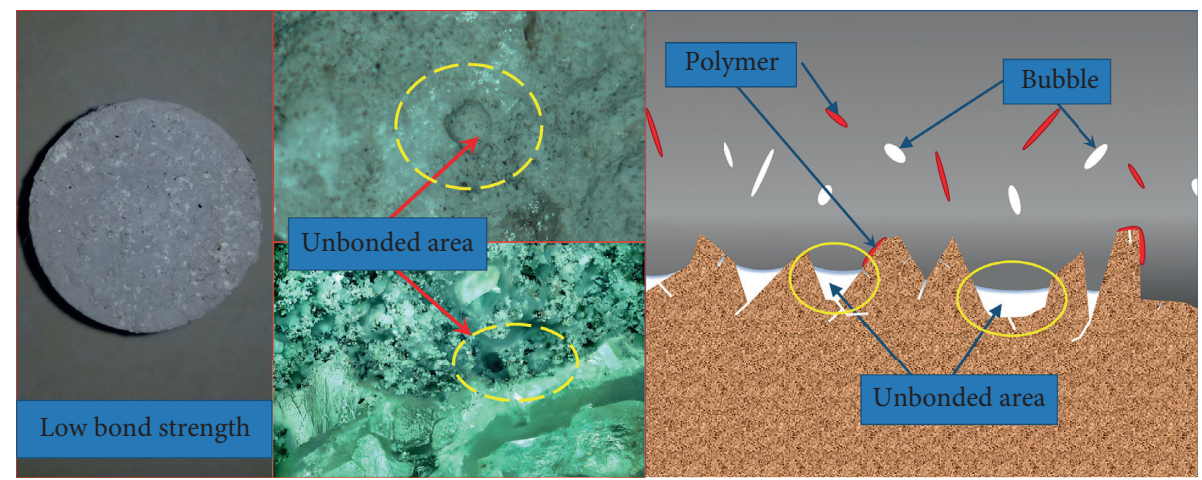

(a)

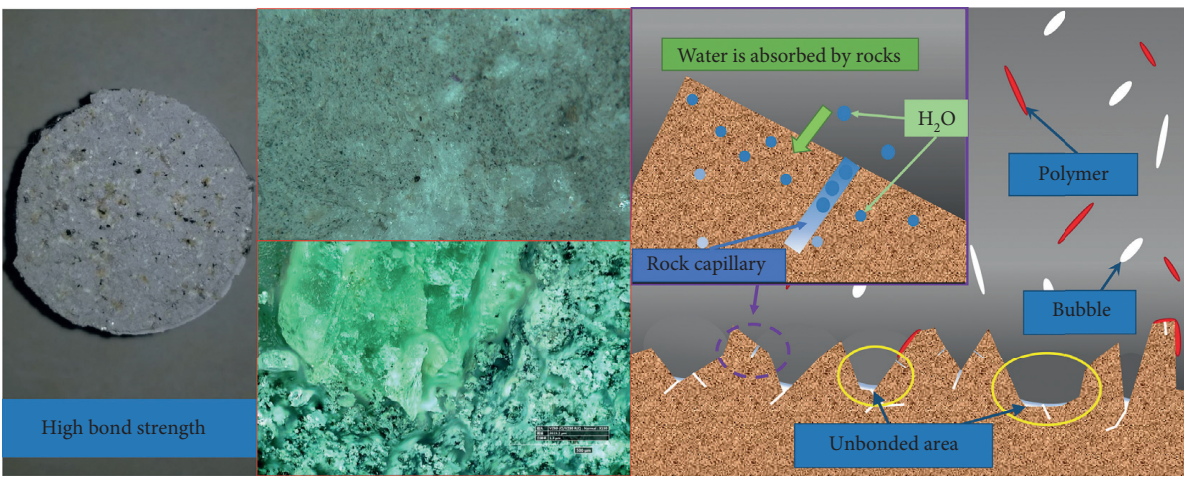

(b)

FIgURE 12: Schematic diagram of bonding of different fluid materials: (a) low-flow material and (b) high-flow material.

from the surface. A high ratio of $\mathrm{P} / \mathrm{C}$ around the contact surface reduced the hydration intensity of TSL materials and mechanical occlusal force, thereby leading to a decline in bonding strength. The decrease in the mechanical occlusal force exceeded the increase in the polymer's bonding strength, which then resulted in the reduction of overall bonding strength. As P/C further increased to $10-14 \%$, the polymer was further separated from the surface and some polymers penetrated into the cracks on the rock surface. The added polymer not only provided the bonding force, e.g., glue, but also formed a polymer film, generating a mechanical occlusal force. Accordingly, the bonding strength rose. Although the hydration of cement around the surface was also affected by a high ratio of $\mathrm{P} / \mathrm{C}$, the increased mechanical occlusal force was further significantly influenced and increased.

After the addition of filling materials, the overall bonding strength dropped and slightly increased when $\mathrm{F} /$ $\mathrm{C}=5 \%$. At a low ratio of $\mathrm{F} / \mathrm{C}$, the filling materials exhibited poor filling performance, and the gel on the material surface shrank during the solidification process. The gel was then separated from the material surface, and the bonding strength dropped. As filling materials were further added, the shrinkage of materials was reduced and the contact area between materials and the wall surface was enhanced, which slightly increased the bonding strength. As F/C further 


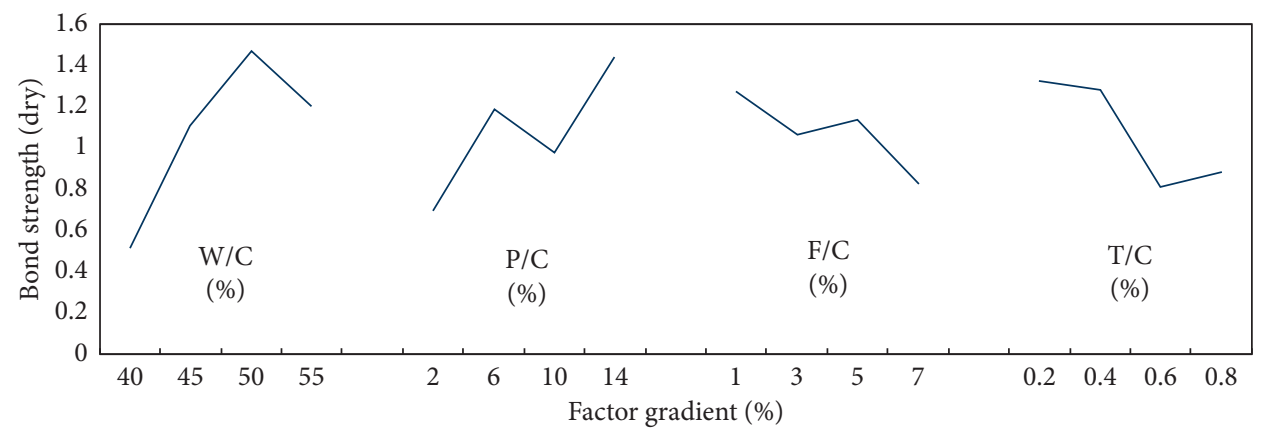

(a)

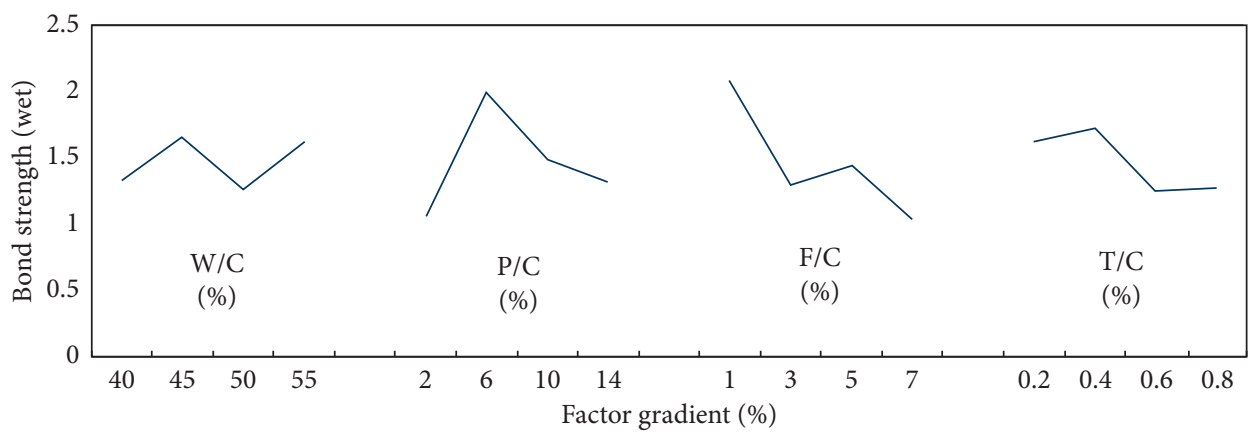

(b)

Figure 13: Influence factor map. (a) Bond strength factor influence diagram (dry wall). (b) Bond strength factor influence diagram (wet wall).

elevated, less gel was produced and the bonding strength dropped. The filling effect of the filling materials and the shrinkage of adhesive materials alternately became the main factors influencing bonding strength. Therefore, at an $\mathrm{F} / \mathrm{C}$ of $3-5 \%$, the bonding strength of materials increased to a certain threshold. Moreover, the bonding strength dropped with the increase in $\mathrm{F} / \mathrm{C}$.

The increase in $\mathrm{T} / \mathrm{C}$ reduced the bonding strength of materials since it increased the viscosity of materials and also reduced the contact area with the material wall surface.

The reasons explaining the effects of $\mathrm{W} / \mathrm{C}$ on the bonding strength of the wet wall were similar to those of the dry wall. By comparing Figures 13(a) and 13(b), it was revealed that $\mathrm{W} / \mathrm{C}$ corresponding to the optimal bonding strength dropped to $45 \%$. Water on the wet wall surface filled cracks in rocks, and free water or the polymer in the materials was not absorbed on the rock surface due to capillary effect. Accordingly, W/C at the interface slightly varied, and the interfacial performance of materials maintained stable. The bonding strength was the highest when $\mathrm{W} / \mathrm{C}=45 \%$.

The effect of $\mathrm{P} / \mathrm{C}$ within a range of $2-10 \%$ on the wet wall surface was similar to that on the dry wall surface. However, as $\mathrm{P} / \mathrm{C}$ further increased to $10-14 \%$, the cracks on the wet wall surface were full of water, and the polymer cannot penetrate into the cracks on the wall. No film was formed, and therefore, the bonding strength dropped steadily.

According to the achieved results, the effect of $\mathrm{F} / \mathrm{C}$ on the wet wall surface was higher than the effect of P/C. However, the variation tendency remained unchanged. This may be due to the fact that the existence of the water film on the surface increased water-absorbing capacity of the filling materials, increased $\mathrm{W} / \mathrm{C}$, and produced defects.

3.4. Optimum Mixture Proportions. Table 11 lists the optimal mixing proportions of various factors. Multiple factors should be taken into account in the preparation of TSLs. Flowability can be regarded as a restricted condition. Based on experimental results, viscosity at a range of 1500-6000 MPa.s was recommendable.

It has been expressed that bending and bonding strengths are quite important [6]. Therefore, bending and bonding strengths were regarded as the indexes, which needed to be remarkably optimized. The cracks should be effectively filled for supporting; i.e., the compressive strength should also be considered. Coal's compressive strength generally ranges from 17 to $25 \mathrm{MPa}$ [67]. The materials with a compressive strength of higher than $17 \mathrm{MPa}$ can thus act as the wedge. The impermeable pressure is generally used for measuring the performance of sealing materials, while the setting time is utilized for evaluating the construction efficiency. Therefore, this study selected compressive strength, impermeability pressure, and setting time as the optimization indexes and determined the optimal proportions by means of the multiindex comprehensive balance method, on which the results are shown in Figures 14 and 15.

By comprehensively analyzing the effects of the gradient changes of various factors on the index, the optimal mixing proportion of the material 1 (i.e., suitable for the dry wall surface) was determined as $\mathrm{W} / \mathrm{C}=50 \%, \mathrm{P} / \mathrm{C}=6 \%, \mathrm{~F} / \mathrm{C}=5 \%$, 
TABLE 11: Optimal ratio of TSL.

\begin{tabular}{|c|c|c|c|c|c|}
\hline Factor & & $\mathrm{W} / \mathrm{C}(\%)$ & $\mathrm{P} / \mathrm{C}(\%)$ & $\mathrm{F} / \mathrm{C}(\%)$ & $\mathrm{T} / \mathrm{C}(\%)$ \\
\hline \multirow{2}{*}{ Setting time } & Initial & 40 & 2 & 7 & 0.2 \\
\hline & Final & 40 & 2 & 5 & 0.2 \\
\hline Seepage pressures & & 45 & 10 & 5 & 0.4 \\
\hline Compressive strength & & 45 & 2 & 1 & 0.8 \\
\hline Flexural strength & & 45 & 6 & 7 & 0.8 \\
\hline \multirow{2}{*}{ Bond strength } & Dry & 50 & 14 & 1 & 0.2 \\
\hline & Wet & 45 & 6 & 1 & 0.4 \\
\hline
\end{tabular}

\begin{tabular}{|c|c|c|c|c|}
\hline & $\begin{array}{c}\mathrm{W} / \mathrm{C} \\
45 \% \Rightarrow 50 \%\end{array}$ & $\begin{array}{c}\mathrm{P} / \mathrm{C} \\
6 \% \Rightarrow 10 \% \Rightarrow 14 \% \gg 6 \%\end{array}$ & $\begin{array}{c}\mathrm{F} / \mathrm{C} \\
1 \% \Rightarrow 5 \% \Rightarrow 7 \%\end{array}$ & $\frac{\mathrm{T} / \mathrm{C}}{0.2 \% \Rightarrow 0.4 \% \Rightarrow 0.8 \%} 0.2 \%$ \\
\hline Osmotic pressure & $320 \%$ & D. $8.3 \%$ \. $4.8 \%$ & Y $4.5 \%$. $10.1 \%$ & 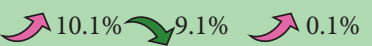 \\
\hline Bond strength (dry) & S $33 \%$ & $\lambda^{47.3 \%} \lambda^{21.3 \%}$ & & $33.4 \%$ \\
\hline Flexural strength & & $46 \%$ 次 $22.5 \%$ & $5.9 \% \frown$ & $\boldsymbol{\lambda}^{1.8 \%} \boldsymbol{\lambda}^{12.6 \%} \boldsymbol{\lambda}^{14.7 \%}$ \\
\hline Initial setting time & $\boldsymbol{\gamma}^{9.5 \%}$ & $\boldsymbol{\lambda}^{17.5 \%} \boldsymbol{八}^{4.3 \%} \boldsymbol{\lambda}^{10.9 \%}$ & $\boldsymbol{\lambda}^{3.3 \%}$ & $\boldsymbol{\lambda}^{0.5 \%} \boldsymbol{\lambda}^{7.5 \%}$ \\
\hline Setting time & $\Omega^{5.7 \%}$ & $\nabla^{6.9 \%} \nabla^{3.7 \%} \unlhd^{64.1 \%}$ & $\boldsymbol{\Omega}^{0.8 \%} \boldsymbol{\Omega}^{9.3 \%} \boldsymbol{\Omega}^{0.8 \%}$ & $y^{6.2 \%} \nearrow^{20.6 \%} \nearrow^{13.2 \%}$ \\
\hline Compression strength & $y^{11.3 \%}$ & $43.7 \%$ & $y^{4.6 \%}$ & 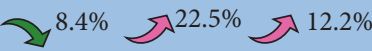 \\
\hline
\end{tabular}

FIGURE 14: Influence of gradient variation of different factors on the dry wall on indicators.

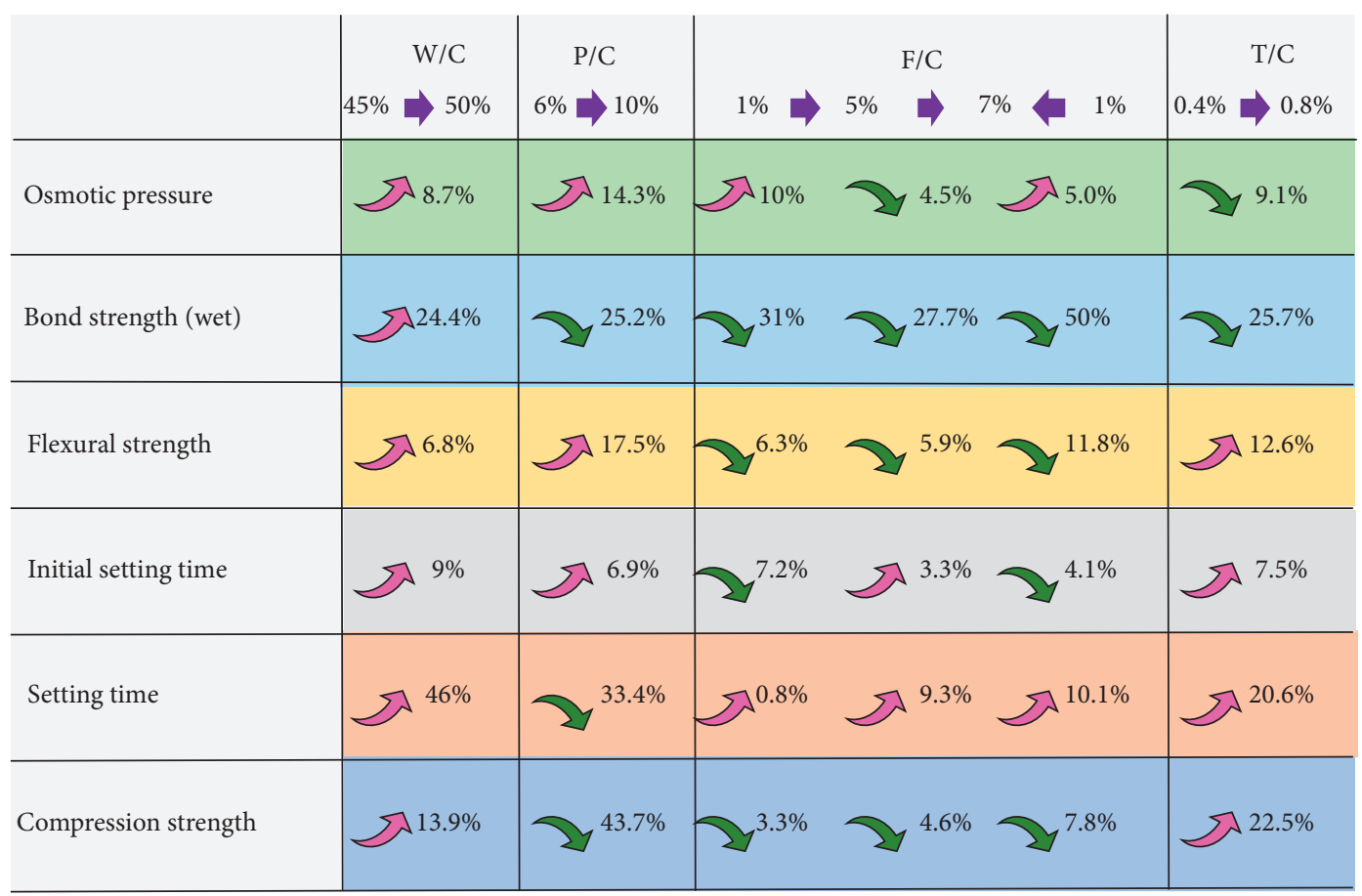

FIGURE 15: Influence of gradient changes of different factors on the wet wall on indicators. 
and $\mathrm{T} / \mathrm{C}=0.4 \%$, while the optimal mixing proportion of the material 2 (i.e., suitable for the wet wall surface) was determined as $\mathrm{W} / \mathrm{C}=45 \%, \mathrm{P} / \mathrm{C}=6 \%, \mathrm{~F} / \mathrm{C}=1 \%$, and $\mathrm{T} / \mathrm{C}=0.4 \%$.

After validation, the viscosity, compressive strength, bending strength, bonding strength, seepage pressure, initial setting time, and final setting time of the prepared TSL materials for the dry wall surface were $2100 \mathrm{MPa} \cdot \mathrm{s}$, 21.175 MPa, $1.979 \mathrm{MPa}, 2.026 \mathrm{MPa}, 0.6 \mathrm{MPa}, 55 \mathrm{~min}$, and $295 \mathrm{~min}$, respectively; while for the wet wall surface, those parameters were $3100 \mathrm{MPa} \cdot \mathrm{s}, 23.718 \mathrm{MPa}, 2.341 \mathrm{MPa}$, $2.358 \mathrm{MPa}, 0.6 \mathrm{MPa}, 50 \mathrm{~min}$, and $285 \mathrm{~min}$, respectively. The prepared materials meet the Europe Self-Compacting Concrete Guidelines (EFNARC) in terms of bending and compressive strength [84]. In addition to economic efficiency in manufacturing, the prepared two different types of TSLs achieved high bonding strength on both dry and wet wall surfaces. By contrast with polyurea TSL-bonded wet ores, the bonding strength of the second type of TSL materials was enhanced by $47 \%$ [85], which can thus be ranked as the "strong" level according to the adhesive test results by Yilmaz [86]. Meanwhile, the seepage pressure was $0.5 \mathrm{MPa}$, suggesting a favorable sealing effect.

\section{Conclusions}

This study used high-elastic polyacrylate and ordinary Portland cement as main components and selected four factors, namely, W/C, P/C, F/C, and T/C, for Taguchi testing. Two different types of TSL materials being appropriate for dry and wet wall surfaces in the mine roadways were prepared. Main conclusions are described in the following:

(1) The optimal range of viscosity of TSL materials was determined. At a viscosity of below $1500 \mathrm{mPa} \cdot \mathrm{s}$, the materials flowed on the wall surface and stable spraying layer cannot be formed. As the viscosity exceeded $6000 \mathrm{mPa} \cdot \mathrm{s}$, the materials were aggregated under a spraying air pressure of $0.6 \mathrm{MPa}$, and the wall-attached impact force was reduced, which then produced a gap in the bonding between the spraying layer and the wall surface and lowered the adhesive quality. Experimental results demonstrated that the materials with a viscosity range of 1500-6000 MPa.s can make a balance between spraying and wall adhesion, which can thus be regarded as an optimal range for the balance in construction and performance.

(2) It was found that the increase in $\mathrm{W} / \mathrm{C}$ can weaken the effect of the tackifier in the materials, and $\mathrm{P} / \mathrm{C}$ was the main factor influencing the bending and compressive strengths. SEM images also indicated that the addition of an appropriate amount of the polymer enhanced the effect of fibers.

(3) According to the achieved results, W/C was the main factor influencing the bonding strength of the dry wall surface, while $\mathrm{F} / \mathrm{C}$ and $\mathrm{P} / \mathrm{C}$ were two main factors influencing the bonding strength of the wet wall surface. The bonding strength of materials was mainly subjected to the contact area between the material and the wall surface. Through the multiindex comprehensive analysis method, the optimal mixing proportions of the prepared TSL for the dry wall surface were determined as $\mathrm{W} / \mathrm{C}=50 \%, \mathrm{P} /$ $\mathrm{C}=6 \%, \mathrm{~F} / \mathrm{C}=5 \%$, and $\mathrm{T} / \mathrm{C}=0.4 \%$, while the optimal proportions of the prepared TSL for the wet wall were $\mathrm{W} / \mathrm{C}=45 \%, \mathrm{P} / \mathrm{C}=6 \%, \mathrm{~F} / \mathrm{C}=1 \%$, and $\mathrm{T} /$ $\mathrm{C}=0.4 \%$.

\section{Data Availability}

Data of Tables 1-6 show the specific properties of the materials provided by the manufacturers and can be obtained from them. The adhesive test results by Yilmaz were used to support this study and are available in [86].

\section{Conflicts of Interest}

The authors declare that there are no conflicts of interest regarding the publication of this paper.

\section{Authors' Contributions}

All the authors have approved the final manuscript.

\section{Acknowledgments}

This study was funded by projects such as the National Key Research and Development Plan of the 13th Five-Year Period (Grant no. 2017YFC0805203); National Natural Science Foundation of China (Grant nos. 51604163, 51974177, and 51934004); Key Research and Development Program of Shandong (Grant no. 2018GSF116001); Natural Science Foundation of Shandong (Grant nos. ZR201801280006, ZR2019QEE007, and ZR2019MEE115); Exchange Projects of the 43rd Routine Session of the ChinaCzech Committee for Scientific and Technological Cooperation (43-4); Taishan Scholar Project Special Funding. Thanks are due to the experimental conditions provided by the State Key Laboratory of Mining Disaster Prevention and Control Co-founded by Shandong Province and the Ministry of Science and Technology and Junde Robot Co., Ltd.

\section{References}

[1] D. Guner and H. Ozturk, "Creep behaviour investigation of a thin spray-on liner," International Journal of Rock Mechanics and Mining Sciences, vol. 108, no. 1, pp. 58-66, 2018.

[2] J. F. Archibald, J. P. Baidoe, and P. T. Katsabanis, "Rockburst damage mitigation benefits deriving from use of spray-on rock linings," in Proceedings of the Third International Seminar on Surface Support Liners: Thin Spray-on Liners, Shotcrete and Mesh, pp. 169-178, Quebec City, Quebec, Canada, August 2003.

[3] Q. Liu, H. Zhang, and T. Lin, "Study on stability of deep rock roadways in coal mines and their support measures," Chinese Rock Mechanics and Engineering, vol. 2004, no. 21, pp. 3732-3737, 2004. 
[4] H. Kang, "Support technologies for deep and complex roadways in underground coal mines: a review," International Journal of Coal Science \& Technology, vol. 1, no. 3, pp. 261-277, 2014.

[5] H. P. Kang, "Sixty years development and prospects of rock bolting technology for underground coal mine roadways in China," China University of Mining \& Technology, vol. 45, no. 6, pp. 1071-1081, 2016.

[6] D. Guner and H. Ozturk, "Experimental and numerical analysis of the effects of curing time on tensile mechanical properties of thin spray-on liners," Rock Mechanics and Rock Engineering, vol. 49, no. 8, pp. 3205-3222, 2016.

[7] L. Chen and G. Liu, "Airflow-dust migration law and control technology under the simultaneous operations of shotcreting and drilling in roadways," Arabian Journal for Science and Engineering, vol. 44, no. 5, pp. 4961-4969, 2019.

[8] L. J. Han, Z. H. Li, and H. L Wang, "Roadway reinforce ment by backfilling and grouting behind the U-type steel supports and shotcreting-wire netting," Shandong University of Science and Technology (Natural Science), vol. 2002, no. 1, pp. 65-68, 2002.

[9] L. Chen, G. Ma, G. Liu, and Z. Liu, "Effect of pumping and spraying processes on the rheological properties and air content of wet-mix shotcrete with various admixtures," Construction and Building Materials, vol. 225, pp. 311-323, 2019.

[10] G. Pan, P. Li, L. Chen, and G. Liu, "A study of the effect of rheological properties of fresh concrete on shotcrete-rebound based on different additive components," Construction and Building Materials, vol. 224, pp. 1069-1080, 2019.

[11] L. Chen, P. Li, G. Liu, W. Cheng, and Z. Liu, "Development of cement dust suppression technology during shotcrete in mine of China-a review," Journal of Loss Prevention in the Process Industries, vol. 55, pp. 232-242, 2018.

[12] G. Liu, X. Guo, W. Cheng, L. Chen, and X. Cui, "Investigating the migration law of aggregates during concrete flowing in pipe," Construction and Building Materials, vol. 251, Article ID 119065, 2020.

[13] H. Ozturk, "Fracture mechanics interpretation of thin sprayon liner adhesion tests," International Journal of Adhesion and Adhesives, vol. 34, pp. 17-23, 2012.

[14] Z. Li, B. Nocelli, and S. Saydam, "Effect of rock strength and surface roughness on adhesion strength of thin spray-on liners," International Journal of Rock Mechanics and Mining Sciences, vol. 91, pp. 195-202, 2017.

[15] Z. Li, J. Tenney, D. Chalmers, R. Mitra, and S. Saydam, "Application of thin spray-on liners to enhance the predrained coal seam gas quality," Energy Exploration \& Exploitation, vol. 34, no. 5, pp. 746-765, 2016.

[16] E. Komurlu, "Support performances of elastomer thin sprayon liners (TSLs) against the rock burst: a case study," in Proceedings of 12th Regional Rock Mechanics Symposium, Trabzon, Turkey, 2018.

[17] L. H. Moreau, Thin spray-on liners: assessment of support performance under dynamic loading conditions, $\mathrm{Ph} . \mathrm{D}$. thesis, University of British Columbia, Vancouver, Canada, 2006.

[18] J. Archibald and P. Dirige, "Thin, spray-on lining applications for rockburst, blast and fire damage mitigation," in Proceedings of the 41st US Symposium on Rock Mechanics (USRMS), Golden, CO, USA, June 2006.

[19] G. Zhou, S. Li, Y. Ma, J. Ding, and M. Zhang, "Synthesis and properties of a reinforcing dust-cementing material for thin spray-on liners in mine roadways," Advances in Materials
Science Engineering, vol. 2019, Article ID 8486534, 12 pages, 2019.

[20] F.-b. Zhou, B.-b. Shi, Y.-k. Liu, X.-l. Song, J.-w. Cheng, and S.-y. Hu, "Coating material of air sealing in coal mine: clay composite slurry (CCS)," Applied Clay Science, vol. 80-81, pp. 299-304, 2013.

[21] J. Deng, Y. Xiao, J. Lu, H. Wen, and Y. Jin, "Application of composite fly ash gel to extinguish outcrop coal fires in China," Natural Hazards, vol. 79, no. 2, pp. 881-898, 2015.

[22] P. C. Li, Z. Zhou, L. J. Chen, G. M. Liu, W. Xiao, and Q. L. Yu, "Research on dust suppression technology of shotcrete based on new spray equipment and process optimization," Advances in Civil Engineering, vol. 2019, Article ID 4831215, 11 pages, 2019.

[23] G. Liu, W. Cheng, L. Chen, G. Pan, and Z. Liu, "Rheological properties of fresh concrete and its application on shotcrete," Construction and Building Materials, vol. 243, Article ID 118180, 2020.

[24] T. J. Tang, "Research on support technology of diverticulum and roadway under complex and water-rich geological conditions," Anhui Vocational College of Metallurgy and Technology, vol. 28, no. 3, pp. 43-46+55, 2018.

[25] Q. B. Shi, S. Li, and Y. G. Gong, "Comprehensive treatment technology of roadway roof watering under complex geological conditions," Henan Polytechnic University (Natural Science), vol. 35, no. z2, pp. 159-163, 2016.

[26] T. Stacey and X. Yu, "Investigations into mechanisms of rock support provided by sprayed liners," in Proceedings of the 5th International Symposium on Ground Support in Mining Underground Construction, pp. 565-569, Perth, Australia, 2004.

[27] H. Ozturk and D. D. Tannant, "Influence of rock properties and environmental conditions on thin spray-on liner adhesive bond," International Journal of Rock Mechanics and Mining Sciences, vol. 48, no. 7, pp. 1196-1198, 2011.

[28] L. Chen, Z. Zhou, G. Liu, X. Cui, and Q. Dong, "Effects of substrate materials and liner thickness on the adhesive strength of the novel thin spray-on liner," Advances in Mechanical Engineering, vol. 12, no. 2, 2020.

[29] N. Fowkes, J. Teixeiradefreitas, and R. Stacey, "Crack repair using an elastic filler," Journal of the Mechanics and Physics of Solids, vol. 56, no. 9, pp. 2749-2758, 2008.

[30] L. J. Pan and Z. J. Xiong, "Study on properties of cementbased high fluid fracture repairing slurry," Jiangsu Construction, vol. 2, pp. 80-82, 2019.

[31] T. Stacey, "Review of membrane support mechanisms, loading mechanisms, desired membrance performance, and appropriate test methods," Journal of Southern African Institute of Mining Metallurgy, vol. 101, no. 7, pp. 343-351, 2001.

[32] S. Lin, "Application of thin spray-on liners in tunneling support," China Mining Magazine, vol. 20, no. 3, pp. 90-101, 2011.

[33] P. H. Ferreira and A. Piroddi, "The application of GRP and thin spray liner support products in a typical block cave mining method to enhance safety and productivity," Journal of Southern African Institute of Mining Metallurgy, vol. 112, no. 2, pp. 141-150, 2012.

[34] P. Mpunzi, R. Masethe, M. Rizwan, and T. R. Stacey, "Enhancement of the tensile strengths of rock and shotcrete by thin spray-on liners," Tunnelling and Underground Space Technology, vol. 49, pp. 369-375, 2015.

[35] H. Yilmaz, "Comparison of mechanical properties of shotcrete and thin spray-on liner (TSL)," in Proceedings of the 
Conference on Shotcrete for Africa, pp. 251-266, Johannesburg, South Africa, March 2009.

[36] S. Jjuuko and D. Kalumba, "A review of application and benefits of thin spray-on liners for underground rock support in South African mines," in Proceedings of 8th South African Young Geotechnical Engineers Conference, pp. 1-10, Stellenbosch, Western Cape, South Africa, 2014.

[37] P. B. Jensen, Managing the engineering, health and safety aspects of thin spray-on liner application: underground trials at Xstrata nickel sudbury operations, nickel rim south, Ph.D. thesis, Luleå University of Technology, Luleå, Sweden, 2013.

[38] D. Tannant, "Thin spray-on liners for underground rock support," in Proceedings of 17th International Mining Congress and Exhibition of Turkey-IMCET, pp. 57-73, Ankara, Turkey, June 2001.

[39] Q. Liu, H. Y. Zang, J. X. Wang, P. Wu, and X. J. Lv, “An overview of preparation and performance of slag based geopolymer," Shandong University of Science and Technology (Natural Science), vol. 38, no. 3, pp. 43-49, 2019.

[40] L. Jiang, P. Zhang, L. Chen et al., "Numerical approach for goaf-side entry layout and yield pillar design in fractured ground conditions," Rock Mechanics and Rock Engineering, vol. 50, no. 11, pp. 3049-3071, 2017.

[41] S. Chang, S. Choi, C. Lee, T. Kang, J. Kim, and M. Choi, "Performance comparison between thin spray-on liners with different compositions," in Proceedings of the First International Conference on Underground Mining Technology, pp. 79-85, Australian Centre for Geomechanics, Perth, Australia, 2017.

[42] S.-H. Chang, G.-P. Lee, J.-T. Han et al., "An experimental study on the evaluation of early-age mechanical properties of polymer-based thin spray-on liners," Journal of Korean Society For Rock Mechanics, vol. 23, no. 5, pp. 413-427, 2013.

[43] S. B. Zhang, J. S. Wu, Q. Wei, and H. H. Dong, "Theory and practices on thin spray-on technology of coal mine," Coal Science and Technology, vol. 45, no. 4, pp. 1-7, 2017.

[44] Z. Jun, Study on application of the epoxy mortar in a large scale, Ph.D. thesis, Xi'an University of Technology, Xi'an, China, 2005.

[45] S. Yu, Y. Zhou, T. Zhang, and M. He, "Preparation and characterization of acrylate copolymers modified by fluorine and silicon for application in release films," Polymer-Plastics Technology and Engineering, vol. 53, no. 6, pp. 531-538, 2014.

[46] J. A. Lavelle, "Acrylic latex-modified Portland cement," ACI Materials Journal, vol. 85, no. 1, pp. 41-48, 1988.

[47] F.-q. Zhao, H. Li, S.-j. Liu, and J.-b. Chen, "Preparation and properties of an environment friendly polymer-modified waterproof mortar," Construction and Building Materials, vol. 25, no. 5, pp. 2635-2638, 2011.

[48] J. Hot, H. Bessaies-Bey, C. Brumaud, M. Duc, C. Castella, and N. Roussel, "Adsorbing polymers and viscosity of cement pastes," Cement and Concrete Research, vol. 63, pp. 12-19, 2014.

[49] M. Wang, R. Wang, S. Zheng, S. Farhan, H. Yao, and H. Jiang, "Research on the chemical mechanism in the polyacrylate latex modified cement system," Cement and Concrete Research, vol. 76, pp. 62-69, 2015.

[50] M. Wang, R. Wang, H. Yao et al., "Research on the mechanism of polymer latex modified cement," Construction and Building Materials, vol. 111, pp. 710-718, 2016.

[51] Y. Ohama, "Concrete-polymer composites - the past, present and future," Key Engineering Materials, vol. 466, pp. 1-14, 2011.
[52] G. Liu, W. Cheng, and L. Chen, "Investigating and optimizing the mix proportion of pumping wet-mix shotcrete with polypropylene fiber," Construction and Building Materials, vol. 150, pp. 14-23, 2017.

[53] J.-T. Han, G.-P. Lee, S.-H. Chang, and M.-S. Choi, "Effect of polymer content on mechanical properties of thin spray-on liner," Geotechnical Aspects of Underground Construction in Soft Ground, vol. 28, pp. 43-46, 2014.

[54] T. Matschei, B. Lothenbach, and F. P. Glasser, "The role of calcium carbonate in cement hydration," Cement and Concrete Research, vol. 37, no. 4, pp. 551-558, 2007.

[55] Y. Q. Cao, H. Li, Z. Q. Wei, Z. Y. Wei, and J. F. Bai, "Development of a new type of fast thin spray material," Modern Mining, vol. 30, no. 2, pp. 114-115, 2014.

[56] Q. Q. Qiu, J. Nemcik, and I. Porter, "Shear strength testing of glass fibre reinforced thin spray-on liner," Geotechnique Letters, vol. 4, no. 4, pp. 250-254, 2014.

[57] Y. Wang and L. M. Gao, "The applications of powder defoamer in polymer modified cement mortar for waterproof," in Proceedings of 7th National Symposium on Commercial Mortar (7th NCCM), pp. 355-360, Guangzhou, Guangdong, China, 2017.

[58] Institute of Cement Science and New Building Materials, "Method of testing cements-determination of strength," State Bureau of Quality and Technical Supervision, Beijing, China, GB/T 17671-1999, 1999.

[59] China Institute of Water Resources and Hydropower Research, "Test code on polymer-modified coment martor," China Institute of Water Resources and Hydropower Research, Beijing, China, DL/T 5126-2001, 2001.

[60] J. Cao and D. D. L. Chung, "Carbon fiber reinforced cement mortar improved by using acrylic dispersion as an admixture," Cement and Concrete Research, vol. 31, no. 11, pp. 1633-1637, 2001.

[61] Ministry of Housing and Urban-Rural Development of the People's Republic of China, "Technical specification for application of sprayed concrete," Ministry of Housing and Urban-Rural Development of the People's Republic of China, Beijing, China, JGJ/T 372-2016, 2016.

[62] X. J. Zhang, Study on preparation of cementitious capillary crystalline waterproofing materials, Ph.D. thesis, Nanchang University, Nanchang, China, 2012.

[63] China Academy of Building Materials Science, "Apparatus for normal consistency and setting time of cement paste," China Academy of Building Materials Science, Beijing, China, JC/T 727-2005, 2005.

[64] China Academy of Building Materials Science, "Test methods for water requirement of normal consistency,setting time and soundness of the portland cement," General Administration of Quality Inspection and Quarantine of the People's Republic of China, Beijing, China, GB/T 1346-2011, 2011.

[65] China Academy of Building Research, "Water-repellent admixture for mortar and concrete," China Academy of Building Research, Beijing, China, JC 474-2008, 2008.

[66] H. Ozturk and D. D. Tannant, "Thin spray-on liner adhesive strength test method and effect of liner thickness on adhesion," International Journal of Rock Mechanics and Mining Sciences, vol. 47, no. 5, pp. 808-815, 2010.

[67] H. P. Kang and L. P. Si, "Test and analysis of coal and rock mass strength in deep coal mine," Chinese Journal of Rock Mechanics and Engineering, vol. 28, no. 7, pp. 1312-1320, 2009.

[68] H. Ma, Y. Tian, and Z. Li, "Interactions between organic and inorganic phases in PA- and PU/PA-Modified-Cement-Based 
materials," Journal of Materials in Civil Engineering, vol. 23, no. 10, pp. 1412-1421, 2011.

[69] Y. Guo, B. Ma, Z. Zhi et al., "Effect of polyacrylic acid emulsion on fluidity of cement paste," Colloids and Surfaces A: Physicochemical and Engineering Aspects, vol. 535, pp. 139148, 2017.

[70] M. Nehdi, "Why some carbonate fillers cause rapid increases of viscosity in dispersed cement-based materials," Cement and Concrete Research, vol. 30, no. 10, pp. 1663-1669, 2000.

[71] C. Wang, J. C. Lui, C. Zhang, C. Zhang, Z. Y. Li, and D. D. Yin, "Influence and mechanism of $\mathrm{CaCO}_{3}$ on properties and structures of cement-based materials," Hunan University (Natural Sciences), vol. 43, no. 6, pp. 22-28, 2016.

[72] R. J. Sun, Z. Q. Zhao, D. W. Huang, G. F. Xin, S. S. Wei, and G. Zhi, "Effect of fly ash and nano- $\mathrm{CaCO}_{3}$ on the viscosity of cement paste," Applied Mechanics and Materials, vol. 357-360, pp. 968-971, 2013.

[73] P. F. Liu, M. Z. Lan, B. F. Xiang, X. D. Zhao, and S. P. Cui, "Influence of hydroxypropyl methyl cellulose ether on properties of machine spraying mortar," New Buliding Materials, vol. 43, no. 7, pp. 49-52, 2016.

[74] J. Pourchez, B. Ruot, J. Debayle, E. Pourchez, and P. Grosseau, "Some aspects of cellulose ethers influence on water transport and porous structure of cement-based materials," Cement Concrete Research, vol. 40, no. 2, pp. 242-252, 2010.

[75] J. L. Nong, Study on bonding performance of polymer-modified cement-based bonding composite, Ph.D. thesis, Hunan University, Changsha, China, 2014.

[76] J. L. Luo, Q. Y. Lia, T. J. Zhao, S. Gao, and S. W. Sun, "Bonding and toughness properties of PVA fibre reinforced aqueous epoxy resin cement repair mortar," Construction and Building Materials, vol. 49, pp. 766-771, 2013.

[77] Z. J. Li, Study on preparation and properties of polymer cement based composites graduate, Ph.D. thesis, Jilin University, Changchun, China, 2017.

[78] H. Najm, A. E. Naaman, T. J. Chu, and R. E. Robertson, "Effects of poly (vinyl alcohol) on fiber cement interfaces. Part I: bond stress-slip response," Advanced Cement Based Materials, vol. 1, no. 3, pp. 115-121, 1994.

[79] G. F. Zhang, R. He, G. R. Zhao, Y. W. Wang, and P. M. Wang, "Effect of hydroxyethyl methyl cellulose on the morphology characteristic of $\mathrm{Ca}(\mathrm{OH})_{2}$ in portland cement paste," Journal of Building Materials, vol. 20, no. 4, pp. 495-500, 2017.

[80] L. Chen, X. Zhang, and G. Liu, "Analysis of dynamic mechanical properties of sprayed fiber-reinforced concrete based on the energy conversion principle," Construction and Building Materials, vol. 254, no. 4, Article ID 119167, 2020.

[81] X. F. Cui, G. M. Liu, C. L. Wang, and Y. D. Qi, "Effects of PET fibers on pumpability, shootability, and mechanical properties of wet-mix shotcrete," Advances in Civil Engineering, vol. 2019, Article ID 2756489, 14 pages, 2019.

[82] E. Sakai and J. Sugita, "Composite mechanism of polymer modified cement," Cement Concrete Research, vol. 25, no. 1, pp. 127-135, 1995.

[83] N. Opedal, J. Todorovic, M. Torsaeter, T. Vralstad, and W. Mushtaq, "Experimental study on the cement-formation bonding," in Proceedings of the SPE International Symposium and Exhibition on Formation Damage Control, Lafayette, LA, USA, Febraury 2014.

[84] The Technical Committee on Thin Spray-On Liners, "Specification and guidelines on thin spray-on liners for mining and tunnelling," The Technical Committee on Thin Spray-on Liners, ENC 250TSL v7.2, 2008.
[85] E. K. Kömürlü and A. Kesimal, "Usability of thin spray-on liners (TSL) for akarsen underground mine in murgul murgul," in Proceedings of the 25th International Mining Congress and Exhibition of Turkey, pp. 89-104, Antalya, Turkey, April 2017.

[86] H. Yilmaz, "Comparison of tensile-bond strength of thin spray-on liners," International Journal of Mining, Reclamation and Environment, vol. 27, no. 1, pp. 56-71, 2013. 